\title{
Penalty of hull and propeller fouling on ship self-propulsion performance
}

\author{
Soonseok Song, Yigit Kemal Demirel, Mehmet Atlar
}

Department of Naval Architecture, Ocean and Marine Engineering, University of Strathclyde, 100 Montrose Street, Glasgow G4 0LZ

\begin{abstract}
Recently, there has been an increasing interest in predicting the effect of biofouling on ship resistance using Computational Fluid Dynamics (CFD). For a better understanding of the impact of biofouling on the fuel consumption and green-house gas emissions of ships, studying the effect of biofouling on ship self-propulsion characteristics is required. In this study, an Unsteady Reynolds Averaged Navier-Stokes (URANS) based fullscale ship self-propulsion model was developed to predict the effect of biofouling on the self-propulsion characteristics of the full-scale KRISO container ship (KCS). A roughness function model was employed in the wall-function of the CFD model to represent the barnacles on the hull, rudder and propeller surfaces. A proportional-integral (PI) controller was embedded in the simulation model to find the self-propulsion point. Simulations were conducted in various configurations of the hull and/or propeller fouling. Finally, the effect of biofouling on the self-propulsion characteristics have been investigated.
\end{abstract}

Keywords: Biofoulilng; ship self-propulsion; KRISO container ship (KCS); Computational Fluid Dynamics (CFD); ship resistance

\section{Introduction}

The unwanted accumulation of microorganisms, plants, algae, or animals on the surfaces of submerged, or semisubmerged, natural or artificial objects is termed as 'biofouling'. Marine biofouling often increases the surface roughness of ship hulls and propellers, which results in speed loss at constant power or power increase at a constant speed [1]. Therefore, it is desirable to mitigate the accumulation of biofouling. Marine coatings are prevalently used to keep hull surfaces clean and if applied with a proper cathodic protection system also prevents corrosion [2].

In the field of naval architecture, there has been much attention paid to the critical impacts of biofouling on ship resistance and powering [3-18] as well as the effects on propeller performance [19-23].

The literature shows that the impact of calcareous (hard shell) fouling is particularly critical [3, 5, 14, 24]. Recently, there have been studies using replicated geometries of calcareous fouling, which are recreated through casting, 3D scanning and printing, etc., to investigate the effect of biofouling without introducing the real fouling into experimental facilities [25-28].

The boundary layer similarity law analysis presented by Granville $[29,30]$ has been prevalently used to predict the effect of surface fouling on ship resistance. However, as criticised by Demirel et al. [31], Granville's similarity law analysis is still limited by the assumptions of flat plate and uniform distribution of roughness Reynolds number, $k^{+}$, and the roughness function, $\Delta U^{+}$. Recently, the use of Computational Fluid Dynamics (CFD) is considered as an effective alternative to overcome the limitations of Granville's similarity law analysis [32]. The merit of using CFD is that the distribution of the local friction velocity, $u_{\tau}$, is dynamically computed for each discretised cell, and therefore the dynamically varying roughness Reynolds number, $k^{+}$, and corresponding roughness function, $\Delta U^{+}$, can be considered in the computation. The three-dimensional (3D) effects can also be taken into account, and the simulations are free from the scale effects if they are modelled in full-scale.

Accordingly, there have been increasing number of studies utilising CFD simulations to predict the effect of biofouling on ship resistance and marine propeller performance [31, 33-35]. 
Recently, Song et al. [36] employed the roughness functions of barnacles, which was obtained by Demirel et al. [26], in the wall-function of the CFD model to study the effect of barnacles on full-scale ship resistance and other hydrodynamic characteristics. They observed significant increases due to the barnacles in ship frictional resistance (up to $93 \%$ ) and total resistance (up to $73 \%$ ). Interestingly, the wave making resistance showed a decrease due to the surface fouling while the viscous pressure resistance increases. Further investigations were carried out to investigate the effect of barnacles on the wave profile, pressure distribution along the hull, velocity distribution around the hull and wake flows.

The same method, using the modified wall-functions, was used to investigate the effect of barnacles on a fullscale propeller in open water by Song et al. [37]. The result suggests that the thrust coefficient decreases while the torque coefficient increases with increasing level of surface fouling, which leads to a reduction of the open water efficiency. Further investigations into the roughness effect on the pressure and velocity field, surface pressure and wall shear stress, and propeller vortices were examined.

Although these studies enable us to better understand the effect of biofouling on full-scale ship resistance and propeller characteristics, it is still worth investigating the effect of biofouling on ship self-propulsion characteristics to precisely predict the effect on the required shaft power of the ship with the presence of the hullrudder-propeller interaction. The prediction of the impact of the hull and/or propeller fouling can be used as a cost-benefit analysis, to schedule the hull and/or propeller cleaning, by comparing the cost associated with the dry-docking and cleaning against the economic penalty of the increased fuel consumption.

To the best of the authors' knowledge, there exists no specific study to predict the effect of biofouling on the fullscale ship self-propulsion characteristics using CFD. Therefore, this study aims to fill this gap by developing a CFD model to investigate the effect of barnacles on ship self-propulsion characteristics and perform a systematic analysis on the effects of both the hull fouling and propeller fouling.

In this study, an Unsteady Reynolds Averaged Navier-Stokes (URANS) based full-scale ship self-propulsion model was developed to predict the effect of biofouling on the self-propulsion characteristics of the full-scale KRISO container ship (KCS). The roughness functions of barnacles, obtained by Demirel et al. [26], were employed in the wall-function of the CFD model to simulate the surface roughness of barnacles with varying sizes and coverages. A verification study was performed to examine the numerical uncertainties arising from the spatial and temporal discretisation. A validation study was performed by comparing a model-scale simulation with experimental data and investigating the effect of scale and the presence of the rudder. The CFD simulations were conducted in different configurations of fouling severities (barnacle sizes and coverages) and fouling scenarios (namely; fouled-hull/clean-propeller, clean-hull/fouled-propeller, and fouled-hull/fouled-propeller). Finally, the effect of biofouling on the self-propulsion characteristics have been studied.

This paper is organised as follows: The methodology of the current study is explained in Section 2, including the modified wall-function approach and the roughness function model as well as the fouling conditions, and the propeller controller used for finding the self-propulsion points. The validation and verification studies are presented in Section 3. Finally, the effect of biofouling on ship self-propulsion characteristics are presented in Section 4, while the effect of biofouling on the flow characteristics around the hull and propeller is covered in Section 5 . 


\section{Methodology}

\subsection{Roughness function}

The surface roughness causes an increase in turbulence, and hence the turbulent stress, wall shear stress and finally the skin friction increases. The roughness effect also results in a downward shift of the velocity profile in the loglaw region. This downward shift is termed as the 'roughness function', $\Delta U^{+}$. The non-dimensional velocity profile in log-the law region for a rough surface is then given as

$$
U^{+}=\frac{1}{\kappa} \log y^{+}+B-\Delta U^{+}
$$

The roughness function, $\Delta U^{+}$can be expressed as a function of the roughness Reynolds number, $k^{+}$, defined as

$$
k^{+}=\frac{k U_{\tau}}{v}
$$

It is of note that $\Delta U^{+}$simply vanishes in the case of a smooth condition.

Demirel et al. [26] conducted an extensive series of towing test of flat plates covered with artificial barnacle patches to find the roughness functions of barnacles with varying sizes and coverages. Different sizes of real barnacles, categorised as small, medium and big regarding their size, were 3D scanned and printed into artificial barnacle patches. From the experimental results, they found that the roughness functions of the barnacles follow the Colebrook type roughness function model of Grigson [38], given by

$$
\Delta U^{+}=\frac{1}{\kappa} \ln \left(1+k^{+}\right)
$$

Table 1 compares the roughness length scales for the fouling conditions of different barnacle sizes and coverage densities and Figure 1 shows the roughness functions obtained from the experiment and the roughness functions.

Table 1 Roughness length scales of the test surfaces, adapted from Demirel et al. [26]

\begin{tabular}{llrlr}
\hline Test surface & $\begin{array}{l}\text { Barnacle } \\
\text { type }\end{array}$ & Surface coverage (\%) & $\begin{array}{l}\text { Barnacle height } \\
h(\mathrm{~mm})\end{array}$ & \multicolumn{2}{l}{$\begin{array}{l}\text { Representative } \\
\text { roughness height } \\
k_{G}(\mu \mathrm{m})\end{array}$} \\
\hline S10\% & Small & $10 \%$ & 1.25 & 24 \\
S20\% & Small & $20 \%$ & 1.25 & 63 \\
S40\% & Small & $40 \%$ & 1.25 & 149 \\
S50\% & Small & $50 \%$ & 1.25 & 194 \\
M10\% & Medium & $10 \%$ & 2.5 & 84 \\
M20\% & Medium & $20 \%$ & 2.5 & 165 \\
M40\% & Medium & $40 \%$ & 2.5 & 388 \\
M50\% & Medium & $50 \%$ & 2.5 & 460 \\
B10\% & Big & $10 \%$ & 5 & 489 \\
B20\% & Big & $20 \%$ & 5 & \\
\hline
\end{tabular}




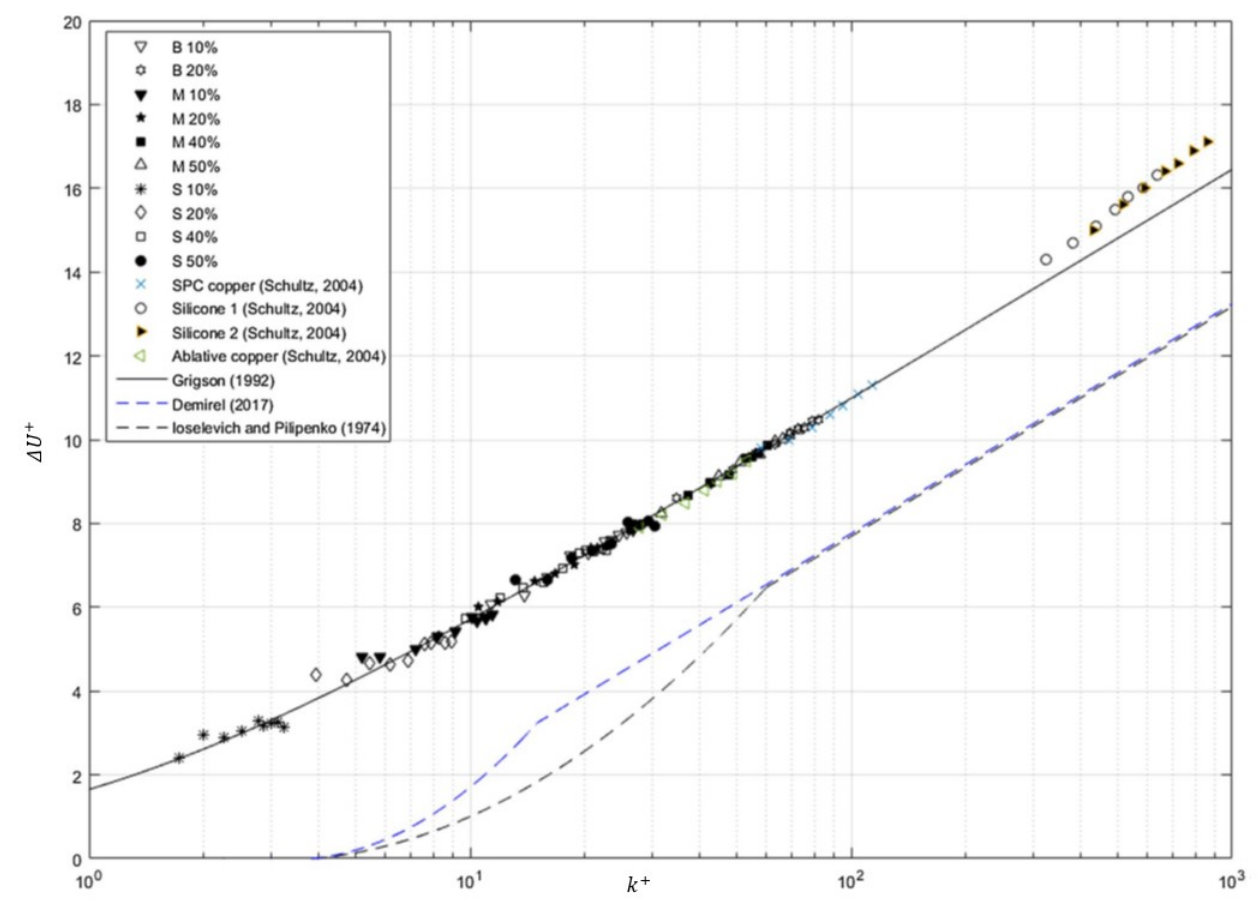

Figure 1 Roughness functions for the fouling conditions and Colebrook type roughness function of Grigson [38], adapted from Demirel et al. [26].

Recently, Song et al. [36] employed this roughness function into the wall-function in the CFD model and conducted simulations of a towed flat plate to validate the modified wall-function approach. The simulation results showed good agreement with the experiment of Demirel et al. [26], and this approach was applied to investigate the effect of barnacles on full-scale ship resistance [36] and propeller performance [37]. In this study, the same approach, using the modified wall-functions, was used to predict the effect of barnacles on self-propulsion performances.

\subsection{Numerical modelling}

\subsubsection{Mathematical formulations}

The proposed CFD model was developed based on the unsteady Reynolds-averaged Navier-Stokes (URANS) method using a commercial CFD software package, STAR-CCM+. The averaged continuity and momentum equations for incompressible flows may be given in tensor notation and Cartesian coordinates as in the following two equations [39].

$$
\begin{gathered}
\frac{\partial\left(\rho \bar{u}_{i}\right)}{\partial x_{i}}=0 \\
\frac{\partial\left(\rho \bar{u}_{i}\right)}{\partial t}+\frac{\partial}{\partial x_{j}}\left(\rho \bar{u}_{i} \bar{u}_{j}+\rho \overline{u_{\imath}^{\prime} u_{j}^{\prime}}\right)=-\frac{\partial \bar{p}}{\partial x_{i}}+\frac{\partial \bar{\tau}_{i j}}{\partial x_{j}}
\end{gathered}
$$

in which, $\rho$ is density, $\bar{u}_{i}$ is the averaged velocity vector, $\rho \overline{u_{\imath}^{\prime} u_{\jmath}^{\prime}}$ is the Reynolds stress, $\bar{p}$ is the averaged pressure, $\bar{\tau}_{i j}$ is the mean viscous stress tensor components. This viscous stress for a Newtonian fluid can be expressed as

$$
\bar{\tau}_{i j}=\mu\left(\frac{\partial \bar{u}_{i}}{\partial x_{j}}+\frac{\partial \bar{u}_{j}}{\partial x_{i}}\right)
$$

where $\mu$ is the dynamic viscosity.

In the CFD solver, the computational domains were discretised and solved using a finite volume method. The second-order upwind convection scheme and a first-order temporal discretisation were used for the momentum equations. The overall solution procedure was based on a Semi-Implicit Method for Pressure-Linked Equations (SIMPLE) type algorithm. 
The shear stress transport (SST) $k-\omega$ turbulence model was used to predict the effects of turbulence, which combines the advantages of the $k-\omega$ and the $k-\varepsilon$ turbulence model. This model uses a $k-\omega$ formulation in the inner parts of the boundary layer and a $k-\varepsilon$ behaviour in the free-stream for a more accurate near wall treatment with less sensitivity of inlet turbulence properties, which brings a better prediction in adverse pressure gradients and separating flow [40]. A second-order convection scheme was used for the equations of the turbulent model.

For the free surfaces, the Volume of Fluid (VOF) method was used with High Resolution Interface Capturing (HRIC).

\subsubsection{Geometry and boundary conditions}

A full-scale model of the KRISO container ship (KCS) with rudder and propeller (KP505) was used in this study. The geometry and the principal particulars of the KCS are presented in Figure 2 and Table 2, while those for the KP505 propeller are given in Figure 3 and Table 3.

\section{1}

$\stackrel{t^{2} \times x}{\longrightarrow}$

Figure 2 Geometry of the KCS with rudder and propeller

Table 2 Principal particulars of the KCS in full-scale adapted from Kim et al. [41] and Larsson et al. [42].

\begin{tabular}{llr} 
Length between the perpendiculars & $L_{P P}(\mathrm{~m})$ & 230 \\
Length of waterline & $L_{W L}(\mathrm{~m})$ & 232.5 \\
Beam at waterline & $B_{W L}(\mathrm{~m})$ & 32.2 \\
Depth & $D(\mathrm{~m})$ & 19.0 \\
Design draft & $T(\mathrm{~m})$ & 10.8 \\
Wetted surface area with a rudder & $S\left(\mathrm{~m}^{2}\right)$ & 9539 \\
Displacement & $\nabla\left(\mathrm{m}^{3}\right)$ & 52030 \\
Block coefficient & $C_{B}$ & 0.6505 \\
Design speed & $V(\mathrm{knot})$ & 24 \\
Froude number & $F_{n}$ & 0.26 \\
\hline
\end{tabular}

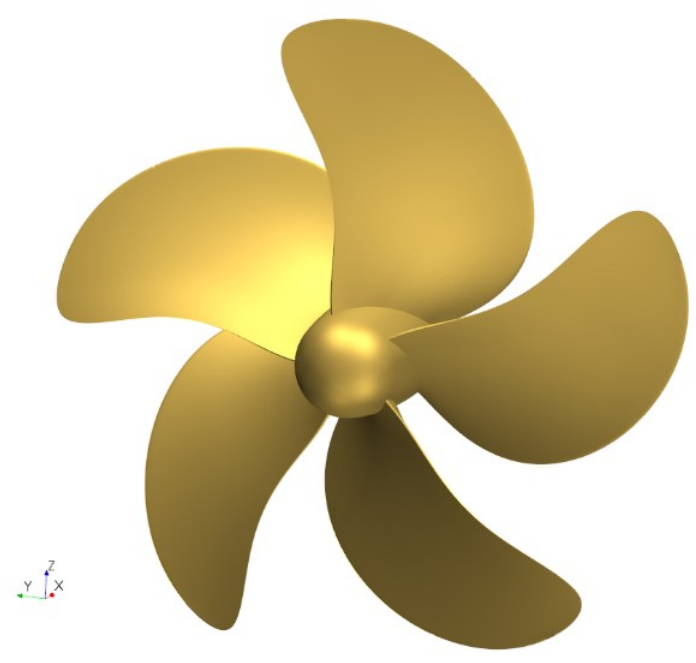

Figure 3 Geometry of the KP505 propeller 


\begin{tabular}{llr}
\hline Propeller Type & & FPP \\
Rotation & & Right Hand \\
No. of Blades & & 5 \\
Section shape & & NAVA66 \\
Propeller diameter & $D_{p}(\mathrm{~m})$ & 7.9 \\
Hub ratio & $D_{h} / D_{p}$ & 0.18 \\
Pitch to diameter ratio & $\mathrm{P} / \mathrm{D}$ & 0.950 \\
Blade area ratio & $\mathrm{Ae} / \mathrm{Ao}$ & 0.800 \\
\hline
\end{tabular}

Figure 4 depicts an overview of the computational domain with the selected boundary conditions in the CFD simulations. The computational domain consists of a stationary region and a rotating region, where the propeller is located (cylinder in the magnifier window in Figure 4). In order to simulate the rotating propeller, a sliding mesh method was used. For the opposite faces in the $x$-direction, the velocity inlet boundary and pressure outlet boundary conditions were applied. On the other hand, the far field boundaries (bottom, top and side walls) were defined as velocity inlets for the representation of deep water and infinite air conditions, as used by other researchers [44- 46]. The inlet, outlet, side wall and bottom boundaries were located at a $2.5 L_{P P}$ distance from the aft perpendicular of the ship, while the top boundary was located at $a 1.25 L_{P P}$ distance. The surface boundary conditions for the hull, rudder and propeller were defined as no-slip walls. For clean hull and clean propeller cases, the smooth type wall-function was used, whereas the rough type wall-functions, containing the roughness functions of barnacles, were used for the rough surfaces of fouled hull and propeller. It is of note that the simulations were conducted in fixed conditions, such that the ship was not allowed to sink or trim.

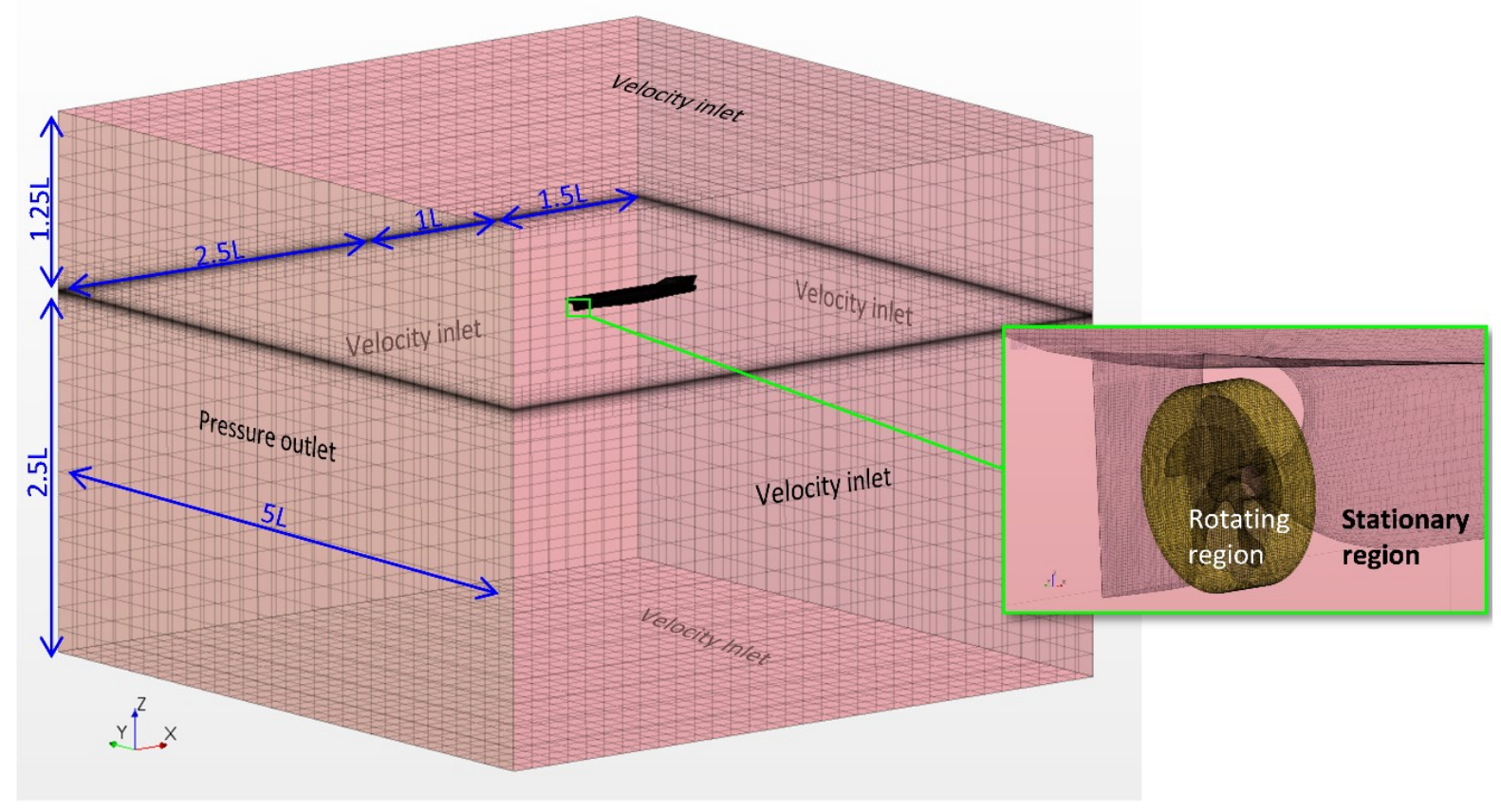

Figure 4 Computational domain and boundary conditions

\subsubsection{Mesh generation}

Mesh generation was performed using the built-in automated meshing tool of STAR-CCM+. Trimmed hexahedral meshes were used. Local refinements were made for finer grids in the critical regions, such as the area around the propeller, near the free surface, the rudder and bulbous bow of the hull as shown in Figure 5.

The prism layer meshes were used for near-wall refinement, and the thickness of the first layer cell on the surface was chosen such that the $y^{+}$values are always higher than 30 , and, also higher than the $k^{+}$values, as suggested by Demirel et al. [31], and CD-Adapco [47]. 


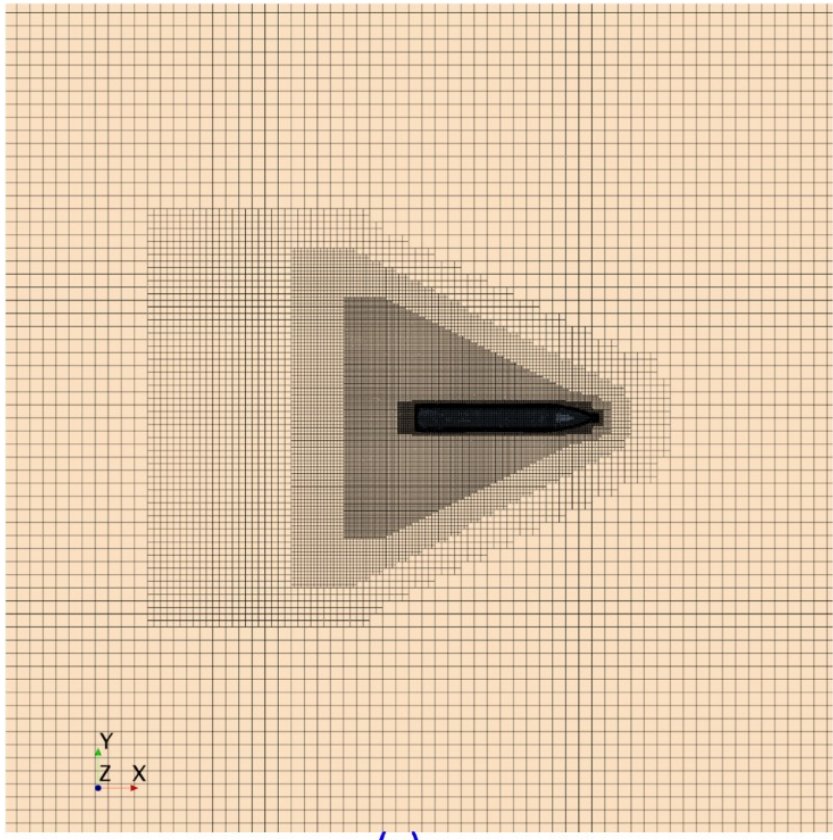

(a)

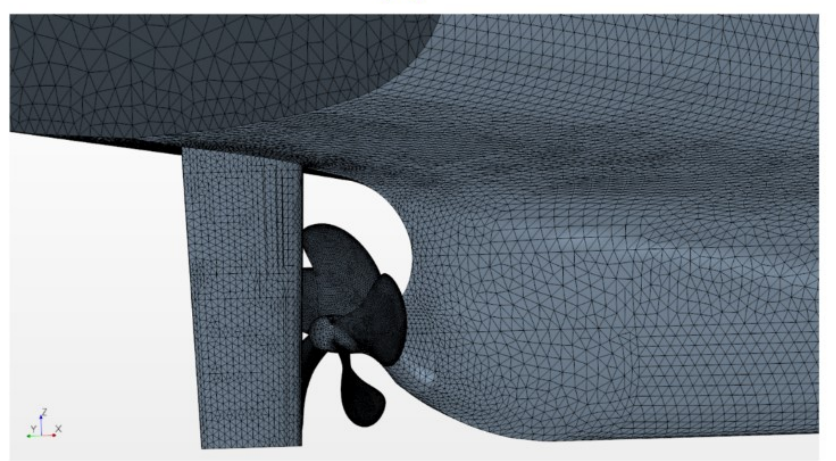

(d)

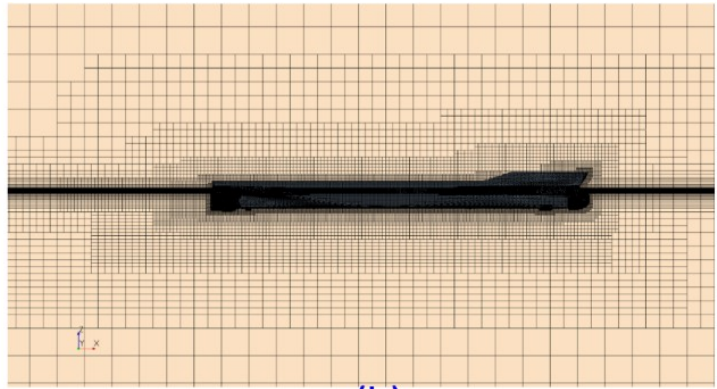

(b)

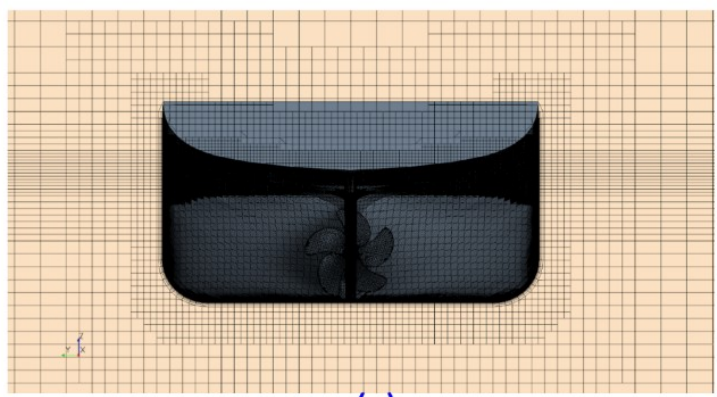

(c)

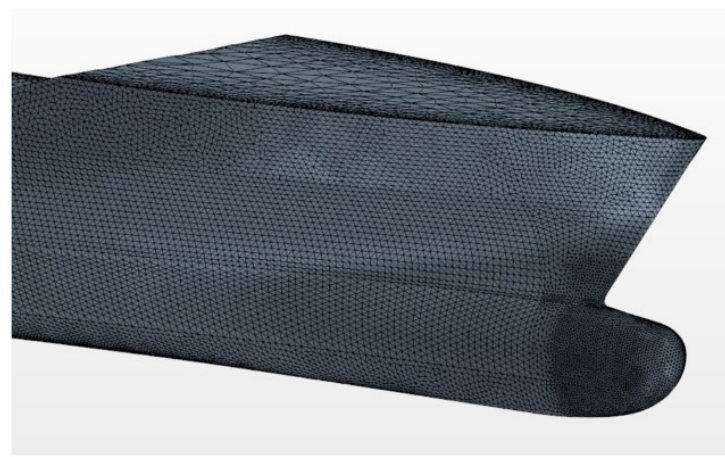

(e)

Figure 5 Volume mesh and surface of the simulation model (a) two view, (b) profile view, (c) rear view, (d) stern, (e) bow

\subsection{Fouling conditions}

The simulations were conducted under combinations of different fouling scenarios and surface conditions (fouling severities). Table 4 shows the different fouling conditions applied to the simulations. The fouling scenarios consist of three fouling configurations namely; 'fouled-hull/clean-propeller', 'clean-hull/fouled-propeller', and 'fouledhull/fouled-propeller' as well as 'clean-hull/clean-propeller' condition as a reference case.

Ten different surface conditions, which can be found in Table 1, were then applied for the three fouling scenarios except for clean-hull/clean-propeller condition. Therefore, a total of 31 different simulations were carried out in this study ( 1 smooth and $3 \times 10$ fouled conditions).

Table 4 Fouling conditions of different fouling scenarios and surface conditions

\begin{tabular}{lccl}
\hline Fouling scenario & $\begin{array}{l}\text { Hull and rudder } \\
\text { fouling }\end{array}$ & Propeller fouling & $\begin{array}{l}\text { Surface condition } \\
\text { (fouling severity) }\end{array}$ \\
\hline Clean-hull/clean-propeller & No & No & Smooth \\
& & & $\begin{array}{l}\mathrm{S} 10 \%, \mathrm{~S} 20 \%, \mathrm{~S} 40 \%, \mathrm{~S} 50 \% \\
\text { Fouled-hull/clean-propeller }\end{array}$ \\
& Yes & No & $\begin{array}{l}\mathrm{M} 10 \%, \mathrm{M} 20 \%, \mathrm{M} 40 \%, \mathrm{M} 50 \% \\
\mathrm{~B} 10 \%, \mathrm{~B} 20 \%\end{array}$ \\
\hline
\end{tabular}




\begin{tabular}{|c|c|c|c|}
\hline Clean-hull/fouled-propeller & No & Yes & $\begin{array}{l}\mathrm{S} 10 \%, \mathrm{~S} 20 \%, \mathrm{~S} 40 \%, \mathrm{~S} 50 \% \\
\mathrm{M} 10 \%, \mathrm{M} 20 \%, \mathrm{M} 40 \%, \mathrm{M} 50 \% \\
\mathrm{~B} 10 \%, \mathrm{~B} 20 \%\end{array}$ \\
\hline Fouled-hull/fouled-propeller & Yes & Yes & $\begin{array}{l}\mathrm{S} 10 \%, \mathrm{~S} 20 \%, \mathrm{~S} 40 \%, \mathrm{~S} 50 \% \\
\mathrm{M} 10 \%, \mathrm{M} 20 \%, \mathrm{M} 40 \%, \mathrm{M} 50 \% \\
\mathrm{~B} 10 \%, \mathrm{~B} 20 \%\end{array}$ \\
\hline
\end{tabular}

\subsection{Propeller controller}

In order to find the self-propulsion point, a proportional-integral (PI) controller was embedded in the simulations, which controls the propeller rotational speed, $n$. The error, $e$, is defined as the difference between the total drag, $R_{T}$, and the thrust of the propeller, $T$, given by

$$
e=R_{T}-T
$$

Then the rotational speed of the propeller, $n$, is determined as

$$
n=n_{0}\left(1+K_{P} e+K_{I} \int_{t_{0}}^{t} e \mathrm{~d} t\right)
$$

where $n_{0}$ is the initial rotational speed of the propeller. $t$ is time, and $t_{0}$ is the time when the PI controller is turned on. $K_{P}$ and $K_{I}$ are the proportional and integral gains of the controller, respectively. The $K_{P}$ and $K_{I}$ values were chosen as

$$
\begin{gathered}
K_{P}=\frac{100}{\rho L_{p p}^{2} V^{2}} \\
K_{I}=\frac{2000}{\rho L_{p p}^{3} V^{2}}
\end{gathered}
$$

Figure 6 gives an example of the propeller revolution, $n$, controlled by the PI controller. The figure illustrates that the $n$ values for the two simulations (clean-hull/clean-propeller and fouled-hull/fouled-propeller, B20\%) remained to $n_{0}$ (in this case, $1.7 \mathrm{rps}$ ) until the PI controller is activated at $t=t_{0}$ (in this case 1,210 s). Then the $n$ values are altered such that the self-propulsion points are achieved.

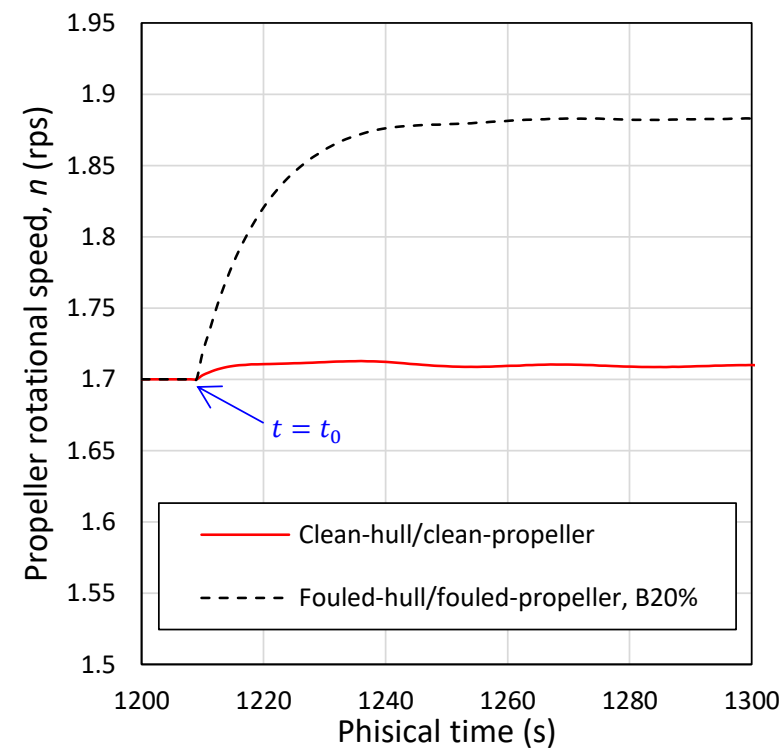

Figure 6 Rotational speed of the propeller controlled by the PI controller 


\section{Validation and verifications}

\subsection{Verification study}

A verification study was carried out to assess the numerical uncertainties of the CFD simulations and to determine sufficient grid-spacing and time step. The Grid Convergence Index (GCI) method based on Richardson extrapolation [48] was used to estimate the order of uncertainties arising from the spatial and temporal discretisation. It is of note that, although the GCI method was firstly intended to be used for spatial convergence studies, it can also be used for a temporal convergence study as shown in Tezdogan et al. [49] and Terziev et al. [50].

According to Celik et al. [51] the apparent order of the method, $p_{a}$, is determined by

$$
\begin{gathered}
p_{a}=\frac{1}{\ln \left(r_{21}\right)}|\ln | \frac{\varepsilon_{32}}{\varepsilon_{21}}\left|+q\left(p_{a}\right)\right| \\
q\left(p_{a}\right)=\ln \left(\frac{r_{21}^{p_{a}}-s}{r_{32}^{p_{a}}-s}\right) \\
s=\operatorname{sign}\left(\frac{\varepsilon_{32}}{\varepsilon_{21}}\right)
\end{gathered}
$$

where $r_{21}$ and $r_{32}$ are refinement factors given by $r_{21}=\sqrt[3]{N_{1} / N_{2}}$ for a spatial convergence study of a 3D model or $r_{21}=\Delta t_{1} / \Delta t_{2}$ for a temporal convergence study. $N$ and $\Delta t$ are the cell number and time step, respectively. $\varepsilon_{32}=\phi_{3}-\phi_{2}, \varepsilon_{21}=\phi_{2}-\phi_{1}$, and $\phi_{k}$ denotes the key variables, i.e. $C_{T}$ and $n$ in this study.

The extrapolated value is calculated by

$$
\phi_{\text {ext }}^{21}=\frac{r_{21}^{p} \phi_{1}-\phi_{2}}{r_{21}^{p}-1}
$$

The approximate relative error, $e_{a}^{21}$, and extrapolated relative error, $e_{e x t}^{21}$, are then obtained by

$$
\begin{gathered}
e_{a}^{21}=\left|\frac{\phi_{1}-\phi_{2}}{\phi_{1}}\right| \\
e_{\text {ext }}^{21}=\left|\frac{\phi_{\text {ext }}^{21}-\phi_{1}}{\phi_{\text {ext }}^{21}}\right|
\end{gathered}
$$

Finally, the fine-grid convergence index is found by

$$
G C I_{\text {fine }}^{21}=\frac{1.25 e_{a}^{21}}{r_{21}^{p}-1}
$$

\subsubsection{Spatial convergence study}

For spatial convergence study, three different resolutions of meshes were generated, which are referred to as fine, medium, and coarse meshes corresponding the cell numbers of $N_{1}, N_{2}$, and $N_{3}$. Table 5 shows the required parameters for the calculation of the spatial discretisation error. The total resistance coefficient, $C_{T}$, and the propeller rotational speed, $n$, of clean-hull/clean-propeller case were used as the key variables. The simulations were conducted at the design speed ( 24 knots) with the Reynolds number of $2.39 \times 10^{9}$. As indicated in the table, the numerical uncertainties of $C_{T}$ and $n$ values for the fine mesh $\left(G C I_{\text {fine }}^{21}\right)$ are $0.06 \%$ and $0.02 \%$ respectively. For accurate predictions, the fine mesh was used for the simulations.

Table 5 parameters used for the calculation of the discretisation error for the spatial convergence study

\begin{tabular}{ccc}
\hline & $C_{T}$ & $n$ \\
\hline$N_{1}$ & $3,742,239$ & $3,742,239$ \\
$N_{2}$ & $2,017,894$ & $2,017,894$ \\
$N_{3}$ & $1,135,263$ & $1,135,263$ \\
\hline
\end{tabular}




\begin{tabular}{crr}
\hline$r_{21}$ & 1.36 & 1.36 \\
$r_{32}$ & 1.33 & 1.33 \\
$\phi_{1}$ & $2.675 \mathrm{E}-03$ & 1.70279 \\
$\phi_{2}$ & $2.684 \mathrm{E}-03$ & 1.70452 \\
$\phi_{3}$ & $2.736 \mathrm{E}-03$ & 1.71433 \\
$\varepsilon_{32}$ & $5.21 \mathrm{E}-05$ & $9.81 \mathrm{E}-03$ \\
$\varepsilon_{21}$ & $8.49 \mathrm{E}-06$ & $1.73 \mathrm{E}-03$ \\
$s$ & 1 & 1 \\
$e_{a}^{21}$ & $0.32 \%$ & $0.10 \%$ \\
$q$ & $1.59 \mathrm{E}-01$ & $1.55 \mathrm{E}-01$ \\
$p_{\mathrm{a}}$ & $6.39 \mathrm{E}+00$ & $6.12 \mathrm{E}+00$ \\
$\phi_{\text {ext }}^{21}$ & $2.674 \mathrm{E}-03$ & $1.702 \mathrm{E}+00$ \\
$e_{\text {ext }}^{21}$ & $0.05 \%$ & $0.02 \%$ \\
$G C I_{\text {fine }}^{21}$ & $0.06 \%$ & $0.02 \%$ \\
\hline
\end{tabular}

\subsubsection{Temporal convergence study}

For the temporal convergence study, three different time steps, namely $\Delta t_{1}, \Delta t_{2}$, and $\Delta t_{3}$, were applied to the simulations using fine meshes. Table 6 shows the required parameters for the calculation of the temporal discretisation error. The total resistance coefficient, $C_{T}$, and the propeller rotational speed, $n$, of clean-hull/cleanpropeller case were used as the key variables. The simulations were conducted at the design speed ( 24 knots) with the Reynolds number of $2.39 \times 10^{9}$. As indicated in the table, the numerical uncertainties of $C_{T}$ and $n$ values for the smallest time steps $\left(G C I_{\Delta t_{1}}^{21}\right)$ are $0.031 \%$ and $0.017 \%$ respectively. For accurate predictions, the smallest time step $\Delta t_{1}=0.0025 \mathrm{~s}$ was used for the simulations. It is of note that ITTC recommends to select the time steps such that the propeller rotates $0.5-2^{\circ}$ per time step [52], and all the simulation cases in this study were conducted within this range.

Table 6 parameters used for the calculation of the discretisation error for the temporal convergence study

\begin{tabular}{crr}
\hline & \multicolumn{1}{l}{$C_{T}$} & \multicolumn{1}{l}{$n$} \\
\hline$\Delta t_{1}$ & $0.0025 \mathrm{~s}$ & $0.0025 \mathrm{~s}$ \\
$\Delta t_{2}$ & $0.0050 \mathrm{~s}$ & $0.0050 \mathrm{~s}$ \\
$\Delta t_{3}$ & $0.0100 \mathrm{~s}$ & $0.0100 \mathrm{~s}$ \\
$r_{21}, r_{32}$ & 2 & 2 \\
$\phi_{1}$ & $2.675 \mathrm{E}-03$ & 1.70279 \\
$\phi_{2}$ & $2.678 \mathrm{E}-03$ & 1.70380 \\
$\phi_{3}$ & $2.696 \mathrm{E}-03$ & 1.70930 \\
$\varepsilon_{32}$ & $1.77 \mathrm{E}-05$ & $5.50 \mathrm{E}-03$ \\
$\varepsilon_{21}$ & $3.11 \mathrm{E}-06$ & $1.01 \mathrm{E}-03$ \\
$e_{a}^{21}$ & $0.12 \%$ & $0.06 \%$ \\
$p_{\mathrm{a}}$ & $2.50 \mathrm{E}+00$ & $2.44 \mathrm{E}+00$ \\
$\phi_{e x t}^{21}$ & $2.675 \mathrm{E}-03$ & $1.703 \mathrm{E}+00$ \\
$e_{e x t}^{21}$ & $0.025 \%$ & $0.013 \%$ \\
$G C I_{\Delta t_{1}}^{21}$ & $0.031 \%$ & $0.017 \%$ \\
\hline
\end{tabular}

\subsection{Validation study}

The simulations for the prediction of the effect of barnacles were conducted in full-scale with propellers and rudders. However, the reference experiment was conducted in model-scale without a rudder [53], and therefore, they cannot be directly compared due to the scale effect and the interaction arising from the rudder. To handle it properly, four different simulations were modelled for the validation, namely; 'model-scale/with-rudder', 'modelscale/without-rudder', 'full-scale/with-rudder', and 'full-scale/without-rudder'. 
Figure 7 schematically illustrates the validation process used in this study. First, a model-scale $\operatorname{KCS}(\lambda=31.6)$ was modelled without a rudder to be compared with the experimental data (validation 1). And then the results from the four different simulations were compared to examine the scale effect and the effect of the presence of rudder.

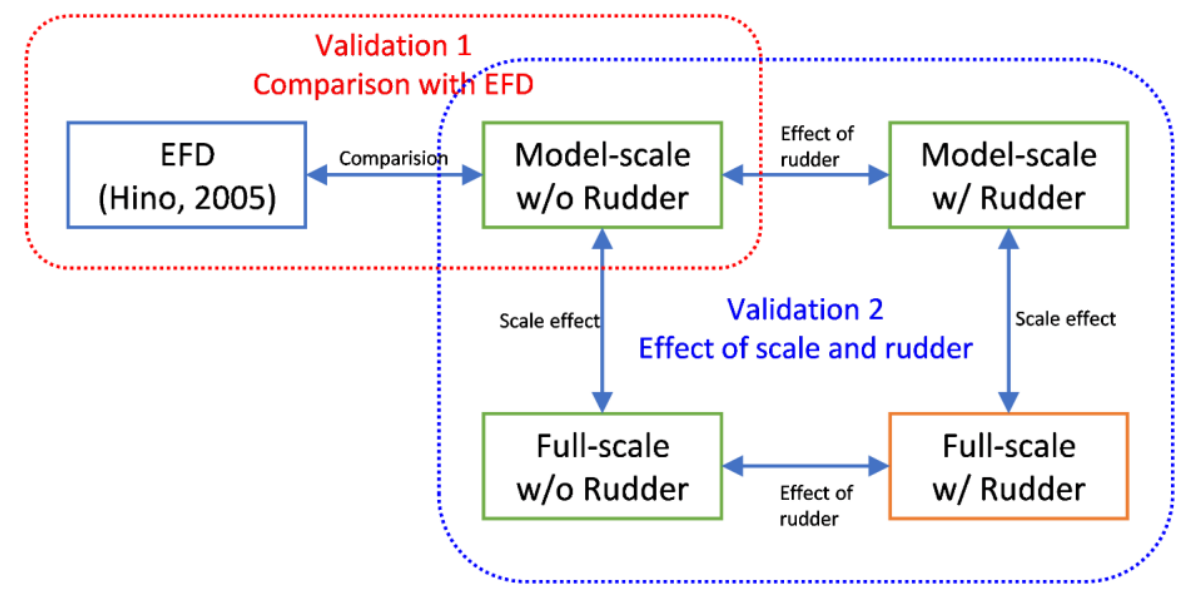

Figure 7 Schematic diagram of the process of the validation study

\subsubsection{Validation 1: comparison with EFD}

As mentioned earlier, the simulation of a model-scale self-propelled $\operatorname{KCS}(\lambda=31.6)$ was modelled without a rudder to be compared with the experimental data of Hino [53]. The simulation was conducted at the design speed $\left(R_{n}=1.40 \times 10^{7}\right)$. The experiment was conducted at the ship point using a skin friction correlation force, $S F C$. In this study, the skin friction correlation force, $S F C$, was calculated as

$$
S F C=\frac{1}{2} \rho_{M} S_{M} V_{M}^{2}(1+k)\left[C_{F 0 M}-\left(C_{F 0 S}+\Delta C_{F}\right)\right]
$$

where, $\rho_{M}, S_{M}$ and $V_{M}$ are the water density, wetted surface area, and speed of the model ship. $C_{F 0 M}$ and $C_{F 0 S}$ are the frictional resistance coefficients at the model-scale and full-scale design speed, respectively. The $C_{F 0}$ values were calculated using ITTC 1957 friction line $\left(C_{F 0}=0.075 /\left(\log _{10} R_{n}-2\right)^{2} . \Delta C_{F}\right.$ is roughness allowance, and $k$ is the form factor. $\Delta C_{F}=0.00027$ and $1+k=1.1$ were used as per the suggestion of Carrica et al. [54].

Figure 8-11 compare the self-propulsion parameters obtained from the current CFD simulation (model-scale without a rudder) with the experimental data of Hino [53], together with the CFD results from Tokyo 2015 CFD workshop, which is available at https://t2015.nmri.go.jp/.

As shown in the figures, generally, the simulation result shows good agreement with the experimental data and the average values of the Tokyo 2015 CFD results. The relative differences between the current CFD and experiment for the $C_{T}, n, K_{T}$, and $K_{Q}$ are $1.07 \%, 0.58 \%, 0.54 \%$, and $5.49 \%$, respectively. The current simulation over-estimate the torque coefficient, $K_{Q}$, compared to the experiment, but it shows a good agreement with the average value of the other CFD results.

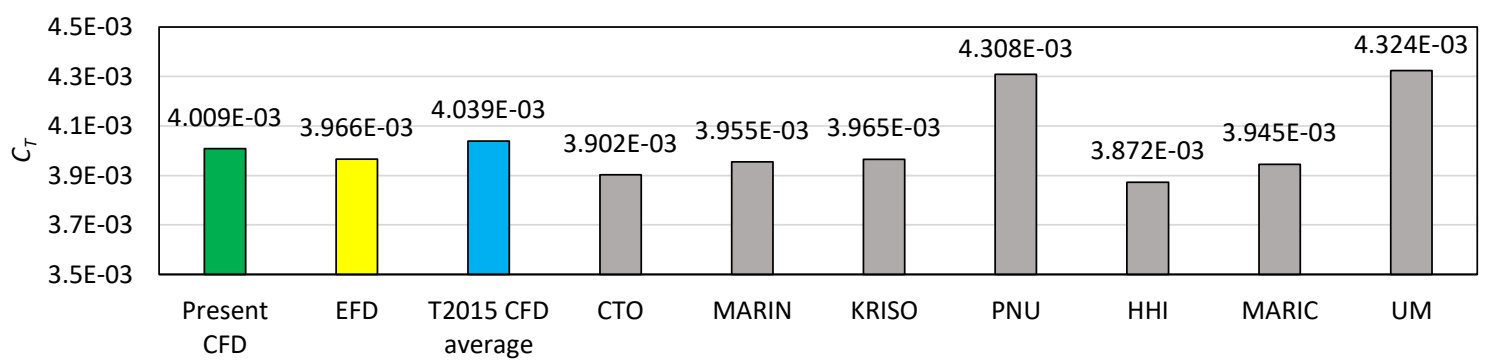

Figure 8 Total resistance coefficient, $C_{T}$, values obtained from the present CFD simulation (model-scale without a rudder), and EFD [53], and other CFD results from the CFD workshop Tokyo 2015 


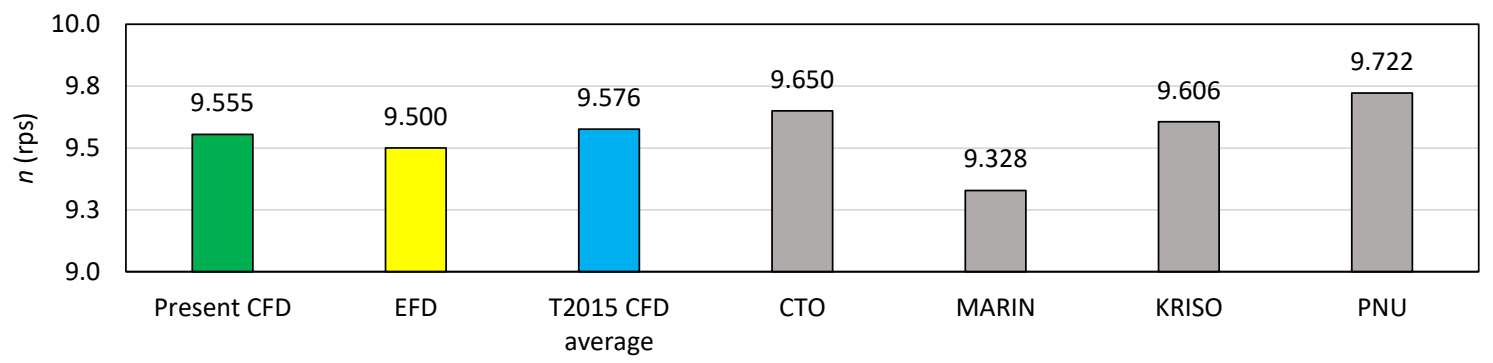

Figure 9 Propeller rotational speed, $n$, values obtained from the present CFD simulation (model-scale without a rudder), and EFD [53], and other CFD results from the CFD workshop Tokyo 2015

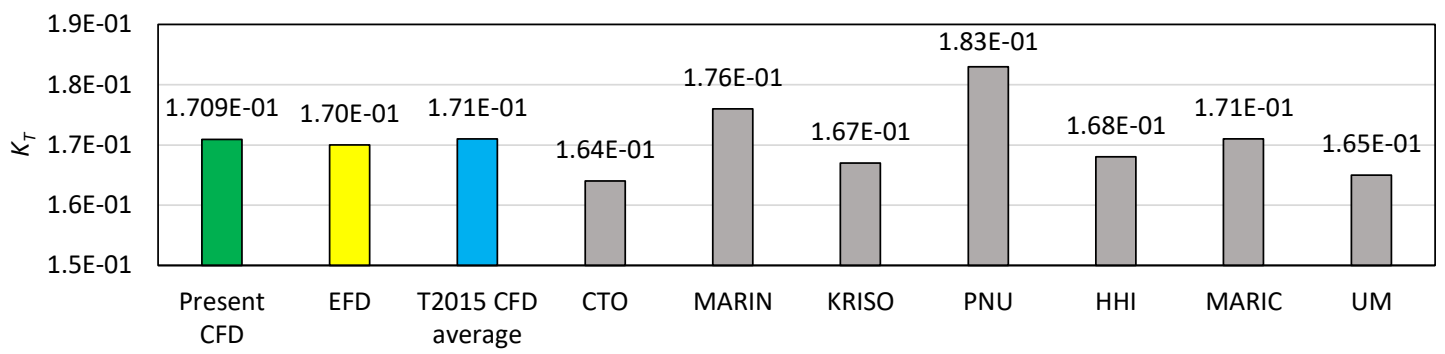

Figure 10 Thrust coefficient, $K_{T}$, values obtained from the present CFD simulation (model-scale without a rudder), and EFD [53], and other CFD results from the CFD workshop Tokyo 2015

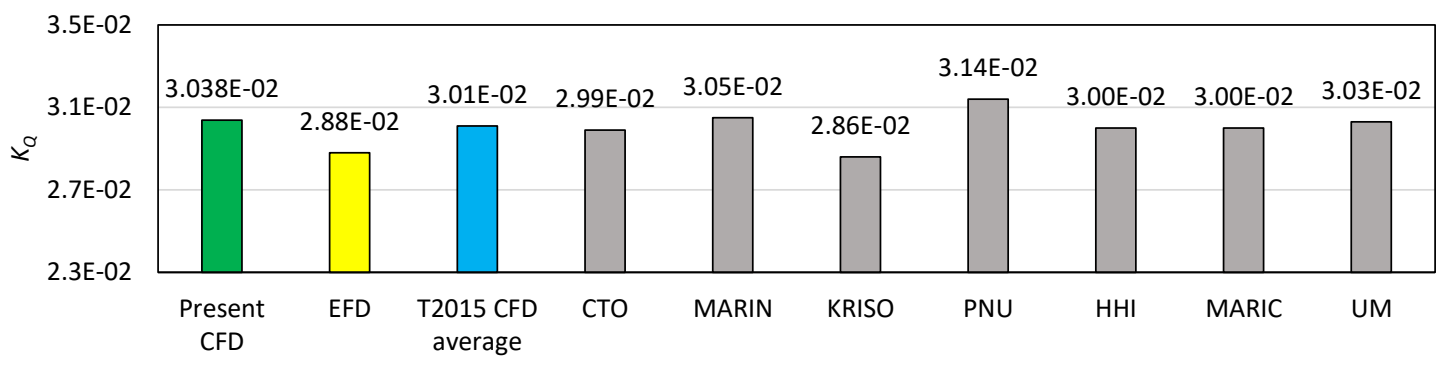

Figure 11 Torque coefficient, $K_{Q}$, values obtained from the present CFD simulation (model-scale without a rudder), and EFD [53], and other CFD results from the CFD workshop Tokyo 2015

\subsubsection{Validation 2: effect of scale and interaction with rudder}

As mentioned earlier, in order to assess the scale effect and the interaction due to the presence of rudder, two model-scale simulations with and without a rudder, and two full-scale simulations with and without rudder were conducted. Figure 12 compares the geometries of the KCS models with and without a rudder.

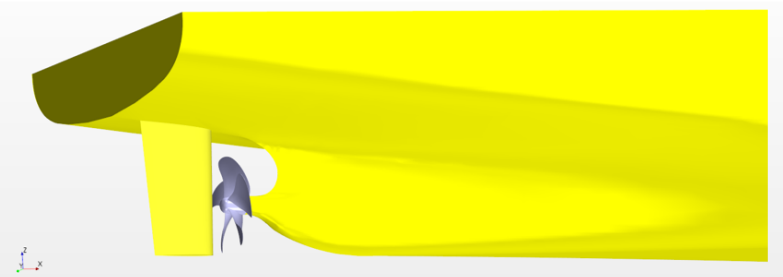

(a) KCS with Rudder

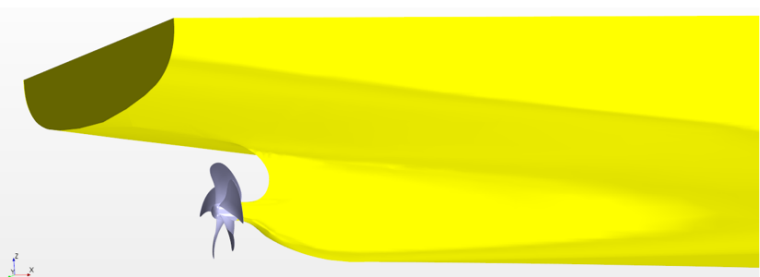

(b) KCS without Rudder

Figure 12 Geometries representing (a) KCS with a rudder and (b) and without a rudder

Table 7 shows the self-propulsion parameters obtained from the four different simulations. The relative differences, $D$, were calculated as $D=(w o R-w R) / w R$, where $w R$ and $w o R$ denote the self-propulsion parameters of with-rudder and without-rudder cases, respectively. For the model-scale simulations, the advance 
coefficients at the self-propulsion points were calculated using the open water curve of the KP505 propeller, obtained by Fujisawa et al. [43], while the full-scale open water curve obtained by the CFD simulation of Song et al. [37] was used for the full-scale advance coefficients.

As shown in the table, and visually illustrated in Figure 13 and 14, the differences between the with-rudder cases and without-rudder cases were consistent in both the scales. Interestingly, in both the scales, although the withoutrudder cases have smaller $C_{T}$ values, the self-propulsion points for these simulations were achieved at higher propeller revolutions, $n$, compared to the with-rudder cases. This can be attributed to the smaller $1-w_{T}$ values (i.e. higher wake fractions, $w_{T}$ ) of with-rudder cases. The with-rudder cases have smaller $1-t$ values (i.e. higher thrust deduction factors, $t$ ). However, the effect of the rudder on the wake fraction was found to be larger than the effect on thrust deduction factor; hence the hull efficiencies, $\eta_{H}$, of with-rudder cases were observed to be larger than the without-rudder cases. The effects of the rudder on the behind-hull propeller efficiency, $\eta_{B}$, were also negative. Finally, the overall propulsive efficiency, $\eta_{D}=\eta_{H} \eta_{B}$, were observed to decrease in the absence of rudder in both the scales, resulting in the increased shaft powers, $S P$.

It is of note that, the experimental study of Reichel [55], which investigates the hull-rudder-propeller interaction, shows very similar results, although the result showed strong dependences on the ship speed.

Table 7 Self-propulsion parameters obtained from the model-scale and full-scale simulations with and without a rudder

\begin{tabular}{lrrrrrrr}
\hline & \multicolumn{3}{c}{ Model-scale } & & \multicolumn{3}{c}{ Full-scale } \\
\cline { 2 - 3 } & w/ Rudder & w/o Rudder & $D(\%)$ & & w/ Rudder & w/o Rudder & D (\%) \\
\hline$C_{T}$ & 0.004089 & 0.004009 & $-1.96 \%$ & & 0.002676 & 0.002583 & $-3.45 \%$ \\
$n^{\prime}=n L_{p p} / V$ & 9.3750 & 9.5548 & $1.92 \%$ & & 1.7028 & 1.7368 & $2.00 \%$ \\
$K_{T}$ & 31.073 & 31.669 & $1.92 \%$ & & 31.723 & 32.356 & $2.00 \%$ \\
$K_{Q}$ & 0.1850 & 0.1709 & $-7.60 \%$ & & 0.1720 & 0.1579 & $-8.19 \%$ \\
$1-t$ & 0.0315 & 0.0304 & $-3.70 \%$ & & 0.0276 & 0.0263 & $-4.60 \%$ \\
$J$ & 0.8164 & 0.8401 & $2.90 \%$ & & 0.7840 & 0.8109 & $3.44 \%$ \\
$1-w_{T}$ & 0.7001 & 0.7293 & $4.18 \%$ & & 0.7144 & 0.7409 & $3.71 \%$ \\
$\eta_{O}$ & 0.7472 & 0.7933 & $6.18 \%$ & & 0.7784 & 0.8234 & $5.78 \%$ \\
$\eta_{H}$ & 0.6650 & 0.6803 & $2.29 \%$ & & 0.6815 & 0.6863 & $0.70 \%$ \\
$\eta_{R}$ & 1.0926 & 1.0589 & $-3.09 \%$ & & 1.0072 & 0.9849 & $-2.22 \%$ \\
$\eta_{B}$ & 0.9856 & 0.9599 & $-2.61 \%$ & & 1.0446 & 1.0233 & $-2.04 \%$ \\
$\eta_{D}$ & 0.6555 & 0.6530 & $-0.38 \%$ & & 0.7119 & 0.7023 & $-1.35 \%$ \\
$S P(\mathrm{~kW})$ & 0.7162 & 0.6914 & $-3.46 \%$ & & 0.7170 & 0.6917 & $-3.54 \%$ \\
\cline { 1 - 1 } & $1.594 \mathrm{E}-01$ & $1.625 \mathrm{E}-01$ & $1.95 \%$ & & $2.700 \mathrm{E}+04$ & $2.733 \mathrm{E}+04$ & $1.22 \%$ \\
\hline
\end{tabular}




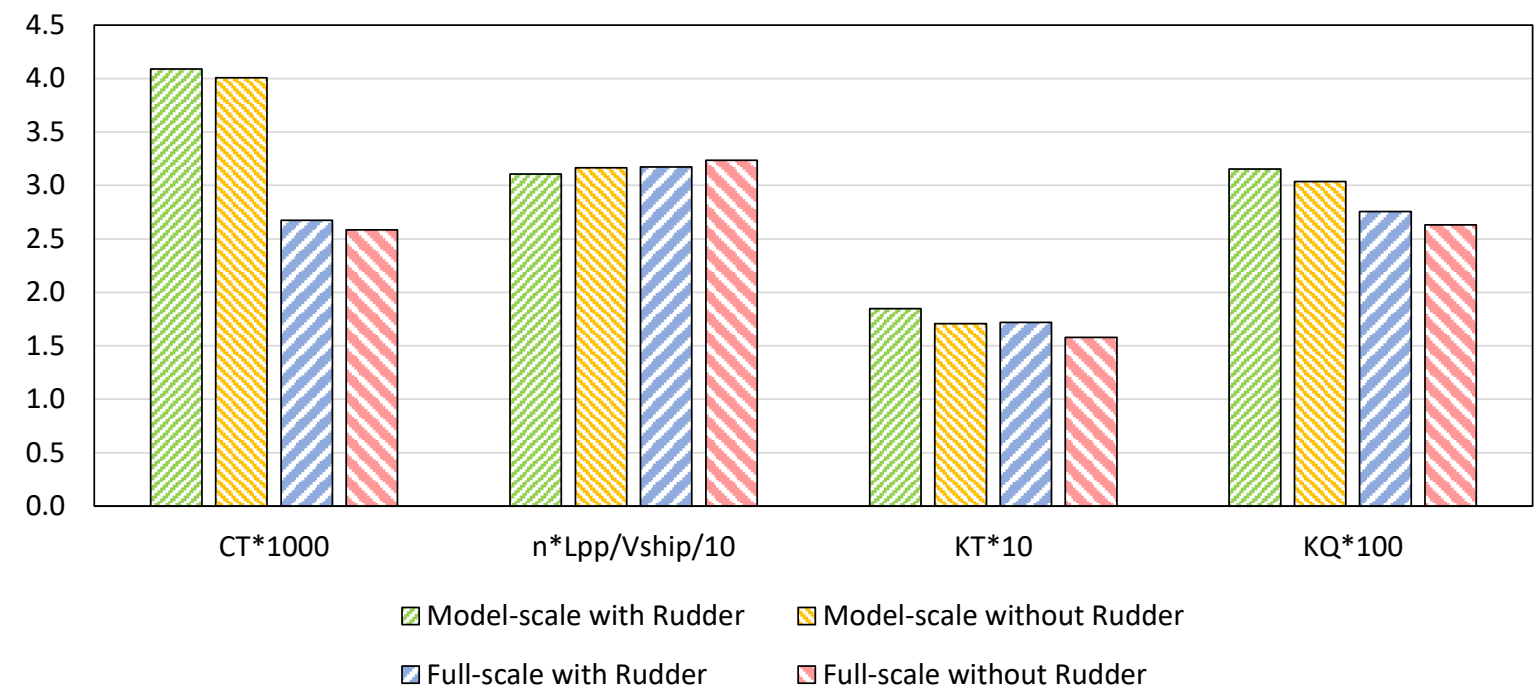

Figure $13 C_{T}, n, K_{T}$ and $K_{Q}$ values at self-propulsion points obtained from the model-scale and full-scale simulations with and without a rudder

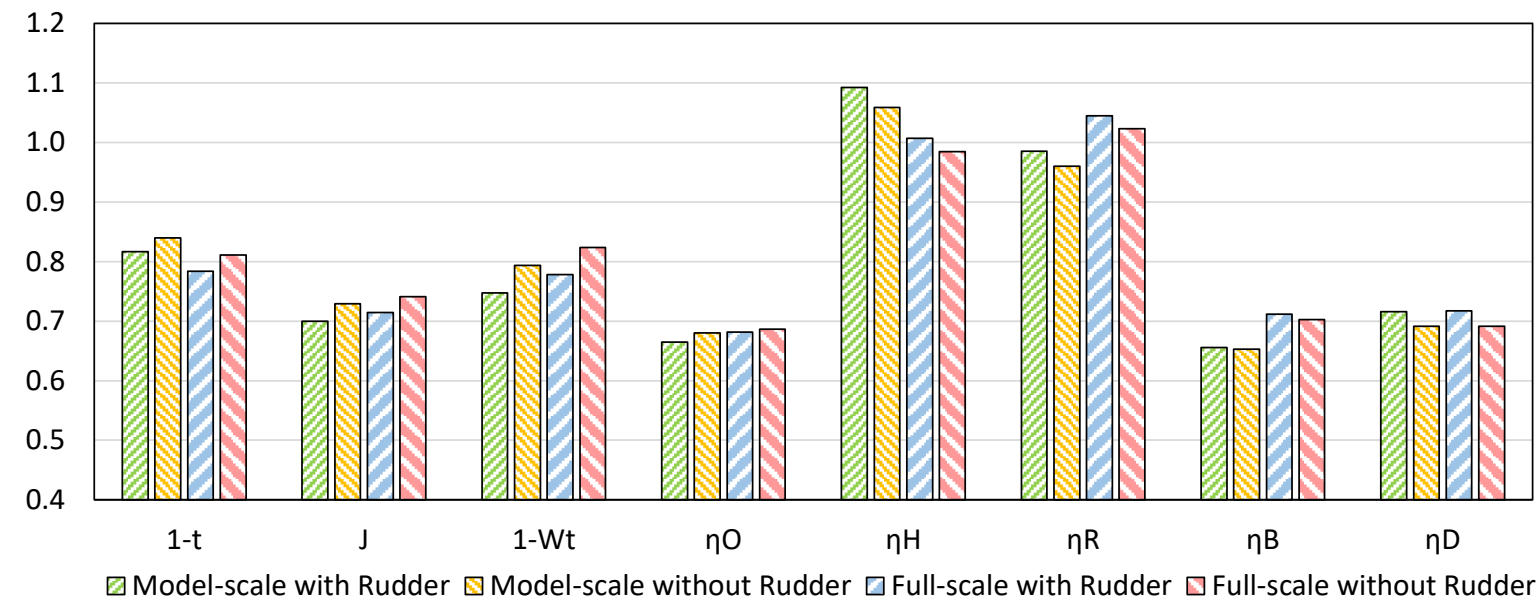

Figure 14 Self-propulsion parameters and propeller efficiencies at self-propulsion points obtained from the model-scale and full-scale simulations with and without a rudder

\section{The effect of biofouling on ship self-propulsion characteristics}

Full-scale self-propulsion simulations were conducted under 31 different conditions as indicated in Table 4 . The self-propulsion parameters obtained from the simulations can be found in Appendix (Table A.1-A.3). The thrust deduction factors, $1-t$, for the fouled-hull cases were calculated using the corresponding $C_{T}$ values of Song et al. [36], while the advance coefficients, $J$, for the fouled-propeller cases were calculated using the corresponding open water curves of Song et al. [37].

\subsection{Effect on total resistance coefficient}

Figure 15 illustrates the total resistance coefficient values, $C_{T}$, obtained from the simulations under the different fouling conditions. In the figure, the $C_{T}$ values are plotted against the representative roughness height, $k_{G}$, of the given surface conditions, which can be found in Table 1 . It should be borne in mind that the $C_{T}$ values with zero representative roughness height, $k_{G}$, represent clean-hull/clean-propeller case. In the figure, the $C_{T}$ values for 
clean-hullffouled-propeller case remained rather constant, whereas those of the fouled-hull conditions show significant increases. From this, it can be deduced that the propeller fouling does not affect the resistance of the ship.

When they are compared with the $C_{T}$ values of the towed KCS by Song et al., [37], the $C_{T}$ values from the selfpropulsion simulations are higher than those of the towed ship simulations, but the trends are similar. This can be explained by the propeller-hull interaction, which is generally referred as 'thrust deduction', where the pressure at the stern is reduced by the propeller accelerating the flow, and the ship resistance is increased due to the reduction of the stern pressure.

It was observed that this thrust deduction mostly appears in the form of the increase in the residuary resistance coefficient, $C_{R}$, rather than frictional resistance coefficient, $C_{F}$. As shown in Figure 17, the $C_{R}$ values of the selfpropulsion simulations are significantly higher than those of the towed ship simulation of Song et al. [36], while the differences between them are relatively minor in the frictional resistance coefficient, $C_{F}$, as can be seen in Figure 16.

Interestingly, unlike the decreasing $C_{R}$ values with the surface fouling severity of the towed ship simulations, the $C_{R}$ values from the self-propulsion simulations under the fouled-hull conditions show rather increasing trends. This can be mostly attributed to the increased propeller rotational speeds, $n$, under those fouling conditions, which causes a higher thrust deduction. The details of the effect of biofouling on the propeller rotational speed, $n$, can be found in the following section.

The increase in $C_{T}, C_{F}$, and $C_{R}$ with B20\% surface condition were $52.0 \%, 90.8 \%$ and $91.0 \%$, respectively, for fouled-hull/clean-propeller case, and 52.3\%, 6.7\%, and 7.2\%, respectively for fouled-hull/fouled-propeller case.

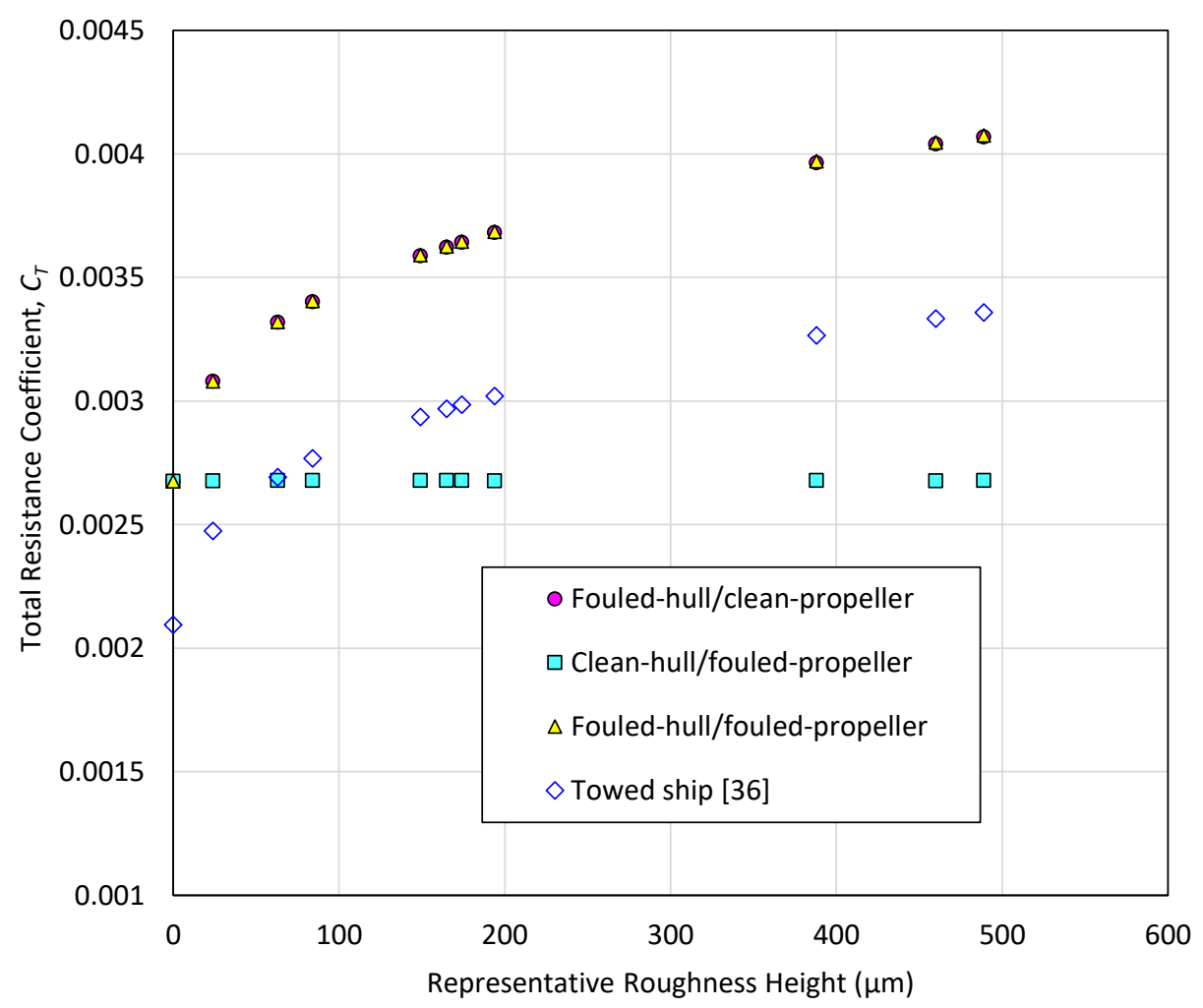

Figure 15 Total resistance coefficient, $C_{T}$, at self-propulsion point under the given fouling conditions, plotted against the representative roughness heights of the surface fouling conditions in Table 1 


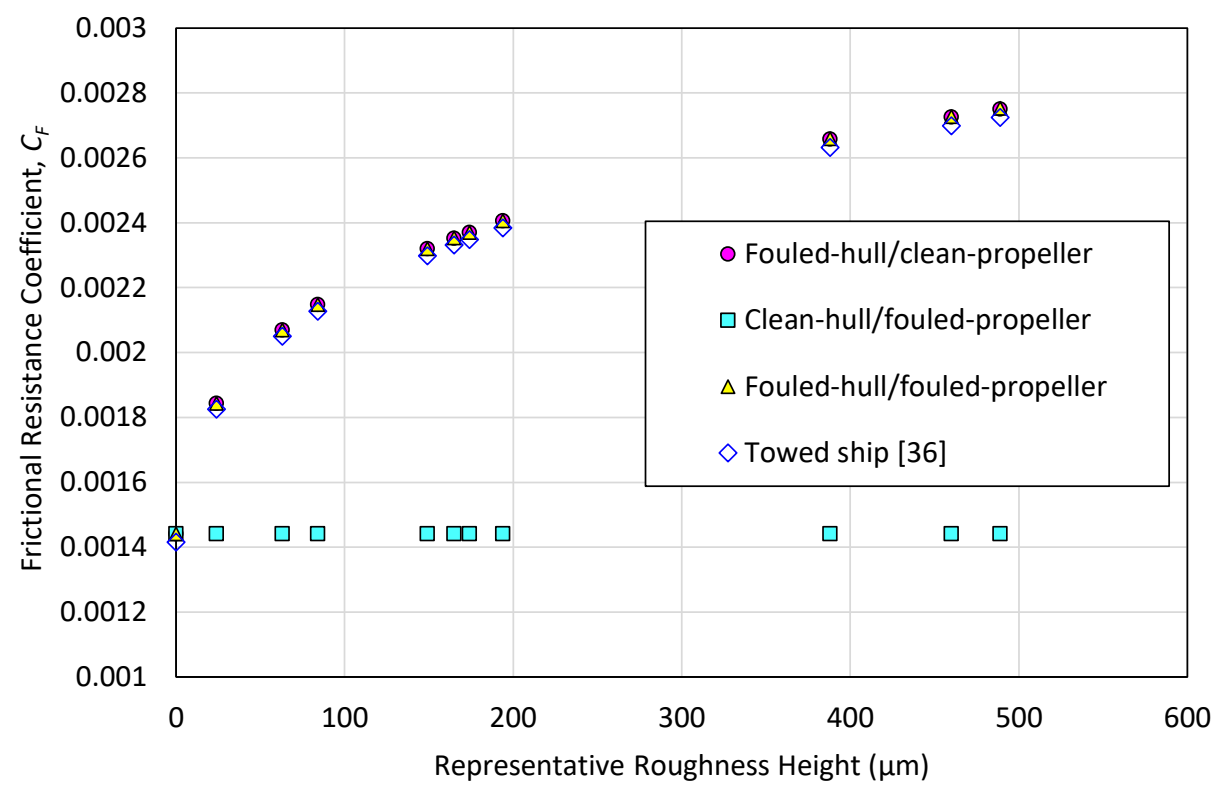

Figure 16 Frictional resistance coefficient, $C_{F}$, at self-propulsion point under the given fouling conditions, plotted against the representative roughness heights of the surface fouling conditions in Table 1

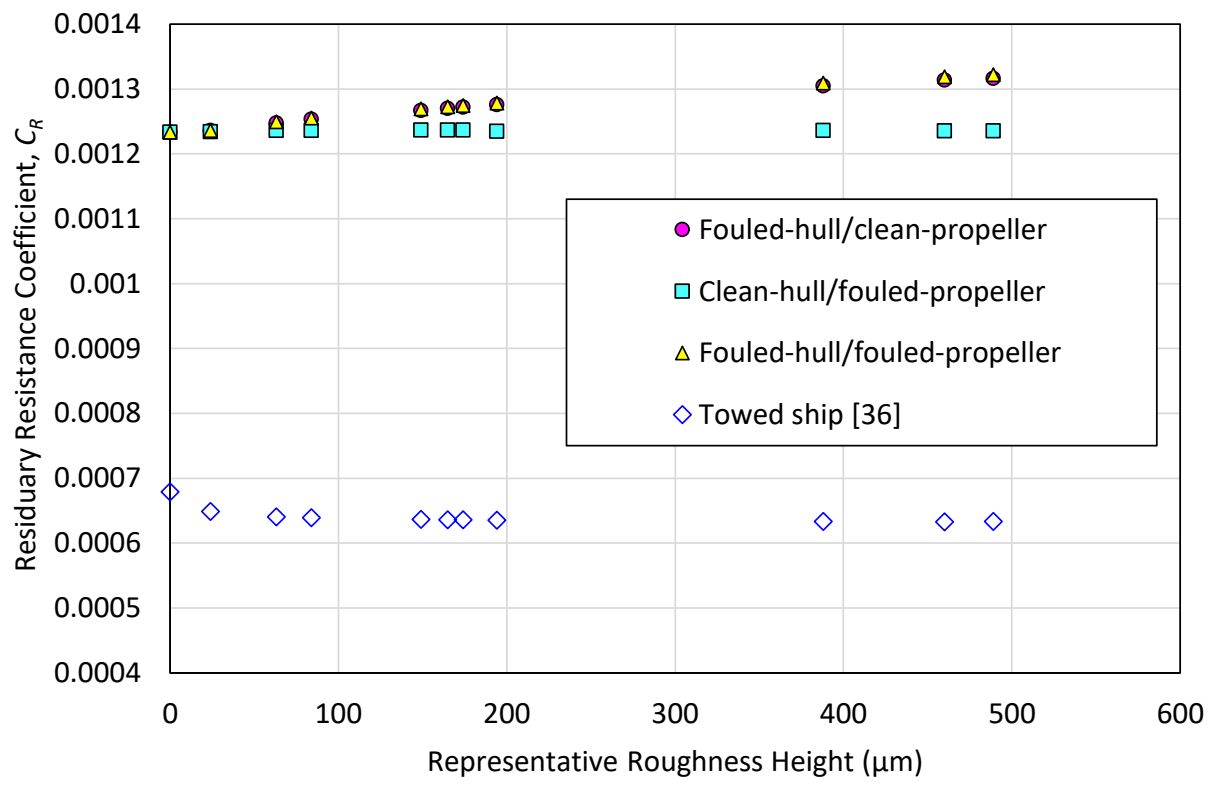

Figure 17 Residuary resistance coefficient, $C_{R}$, at self-propulsion point under the given fouling conditions, plotted against the representative roughness heights of the surface fouling conditions in Table 1

\subsection{Effect on propeller rotational speed}

Figure 18 compares the rotational speed of the propeller, $n$, at the self-propulsion point under the different fouling conditions. The result suggests that hull fouling and propeller fouling both increase the $n$ values at the selfpropulsion point, but the impact of hull fouling is much severe than that of propeller fouling. The reason of the increase in $n$ values under fouled-hull conditions can be ascribed to the increased $C_{T}$ values which were found in Figure 15, while the increase in $n$ values under fouled-propeller conditions can be explained by the decreased thrust at the same advance coefficient, $J$, due to the surface fouling as shown in Figure 19. It means, for a fouledpropeller case a higher $n$ value is required to achieve the same thrust, $T$. 
The increases in $n$ values under fouled-hull/clean-propeller, clean-hull/fouled-propeller, and fouled-hull/fouledpropeller conditions at the most severe surface fouling condition (B20\%) were observed to be $8.1 \%, 2.0 \%$, and $10.1 \%$, respectively.

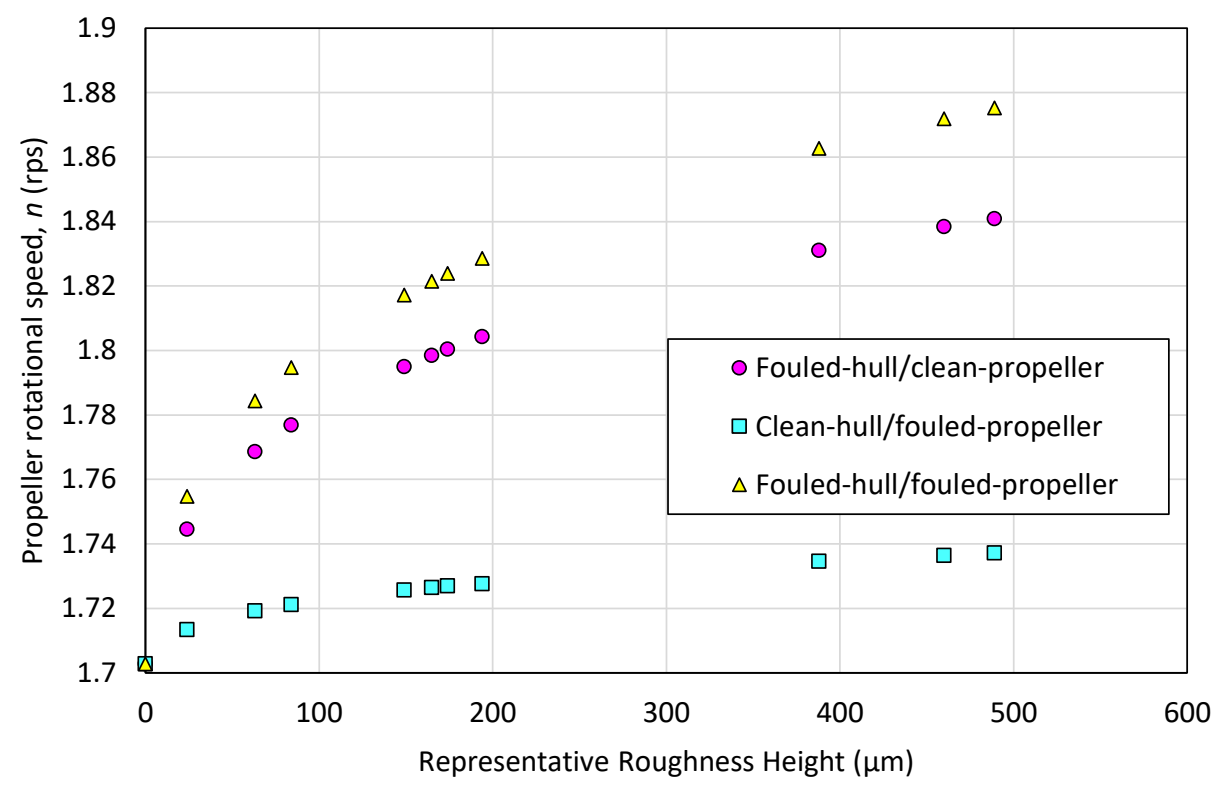

Figure 18 Propeller rotational speed, $n$, at self-propulsion point under the given fouling conditions, plotted against the representative roughness heights of the surface conditions in Table 1

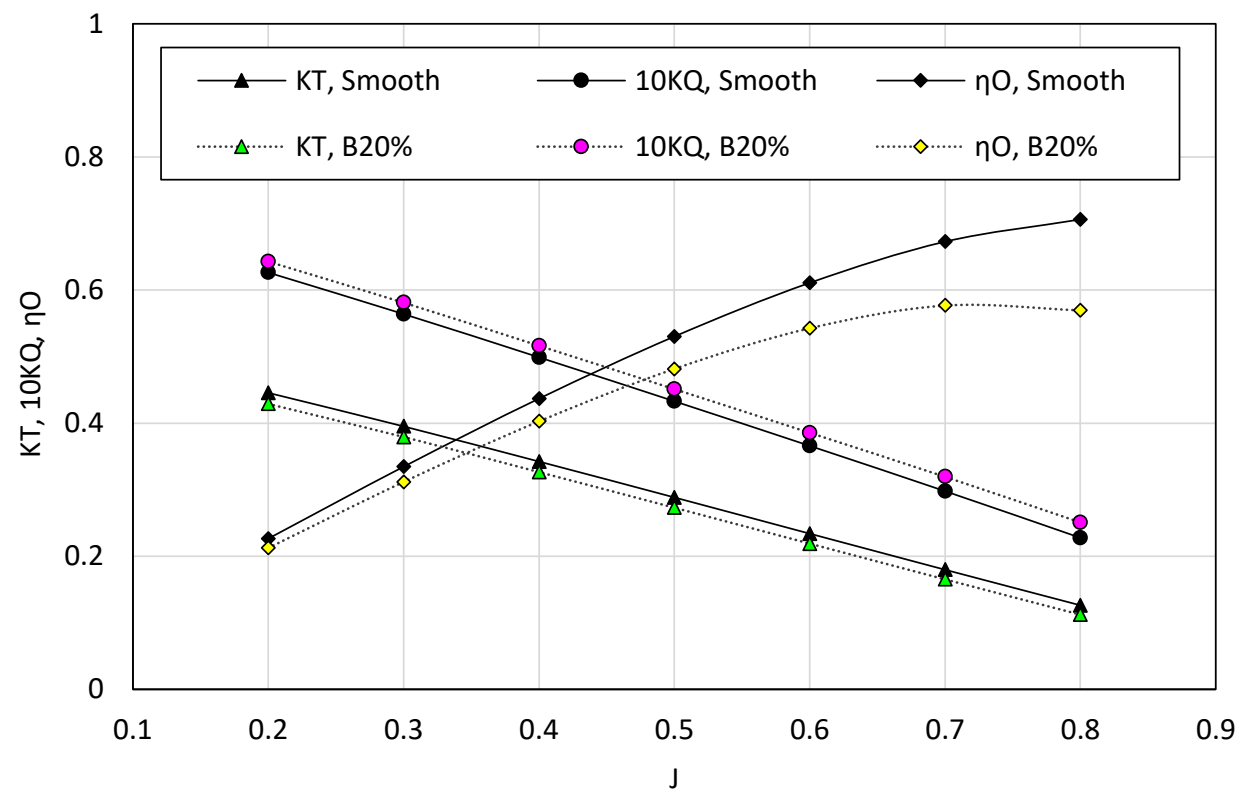

Figure 19 Open water curves for smooth (clean) and fouled (B20\%) propellers, adapted from Song et al. [37]

\subsection{Effect on thrust and torque coefficients}

Figure 20 shows the thrust coefficients, $K_{T}$, at the self-propulsion points under the given fouling conditions. As expected, fouled-hull cases show an increasing trend of $K_{T}$ values with increasing fouling severities. Interestingly, clean-hullffouled-propeller case shows decreasing $K_{T}$ values due to the propeller fouling. This can be explained by the fact that the required thrust, $T$, remains rather constant in this condition due to the constant total resistance as shown in Figure 15. But, the rotational speed of the propeller, $n$, increases due to the propeller fouling as shown in Figure 18. As a result, the $K_{T}=T /\left(\rho n^{2} D^{4}\right)$ values decrease with increasing level of surface fouling. For a 
similar reason, fouled-hull/fouled-propeller case shows smaller $K_{T}$ values compared to those of fouled-hull/cleanpropeller case.

The increases and decrease in $K_{T}$ values under fouled-hull/clean-propeller, clean-hull/fouled-propeller, and fouled-hull/fouled-propeller conditions at the most severe surface fouling condition (B20\%) were observed to be $30.1 \%,-3.8 \%$, and $25.7 \%$, respectively.

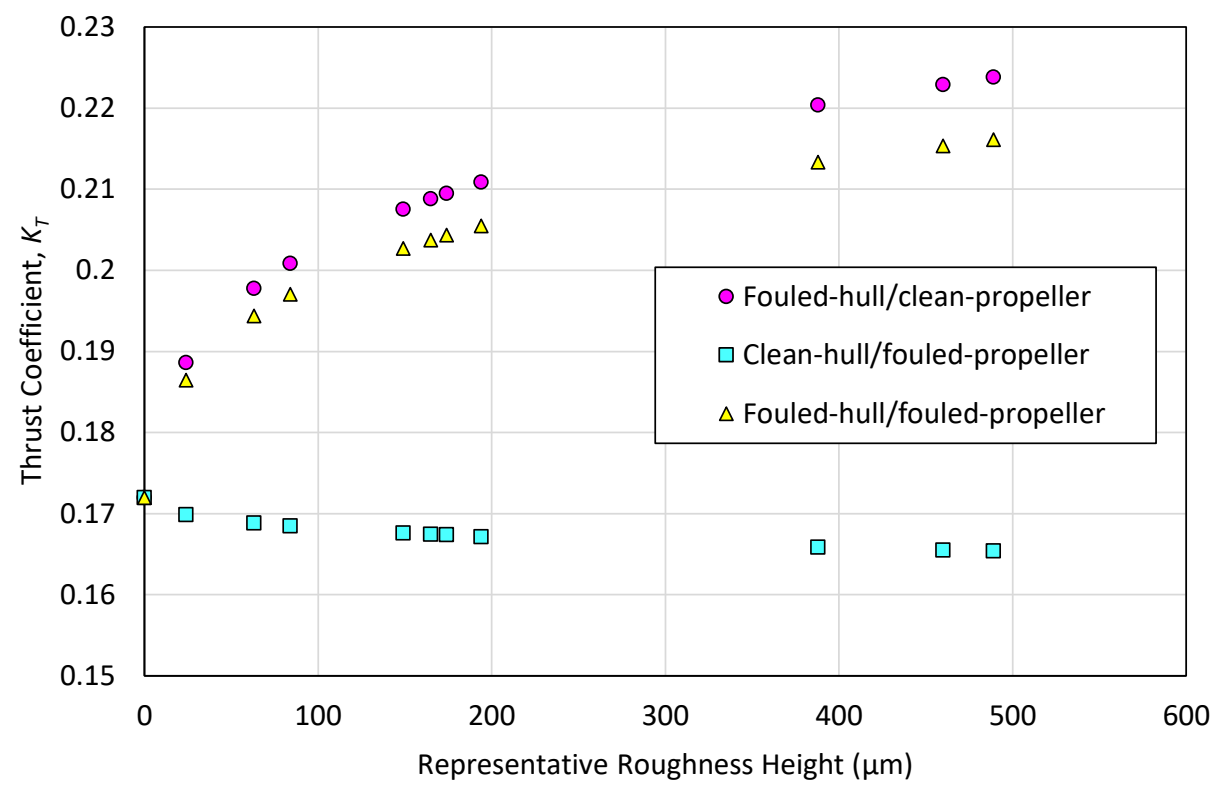

Figure 20 Thrust coefficient, $K_{T}$, at self-propulsion point under the given fouling conditions, plotted against the representative roughness heights of the surface conditions in Table 1

Figure 21 shows the torque coefficients, $K_{Q}$, at the self-propulsion points under the different fouling conditions. Similarly, to the trend of $n$ values, it was shown that the $K_{Q}$ values are affected by both of hull fouling and propeller fouling. The increase in $K_{Q}$ values can be explained by the increase in the propeller rotational speeds, $n$, which results in reduced advance coefficients, $J$. Therefore, the $K_{Q}$ values increase due to the reduced advance coefficients as well as the increased torques, $Q$, for fouled-propeller cases, as shown in Figure 19.

The increases in $K_{Q}$ values for fouled-hull/clean-propeller, clean-hullffouled-propeller, and fouled-hullfouledpropeller conditions at the most severe surface fouling condition (B20\%) were observed to be $24.9 \%, 12.2 \%$, and $36.2 \%$, respectively. 


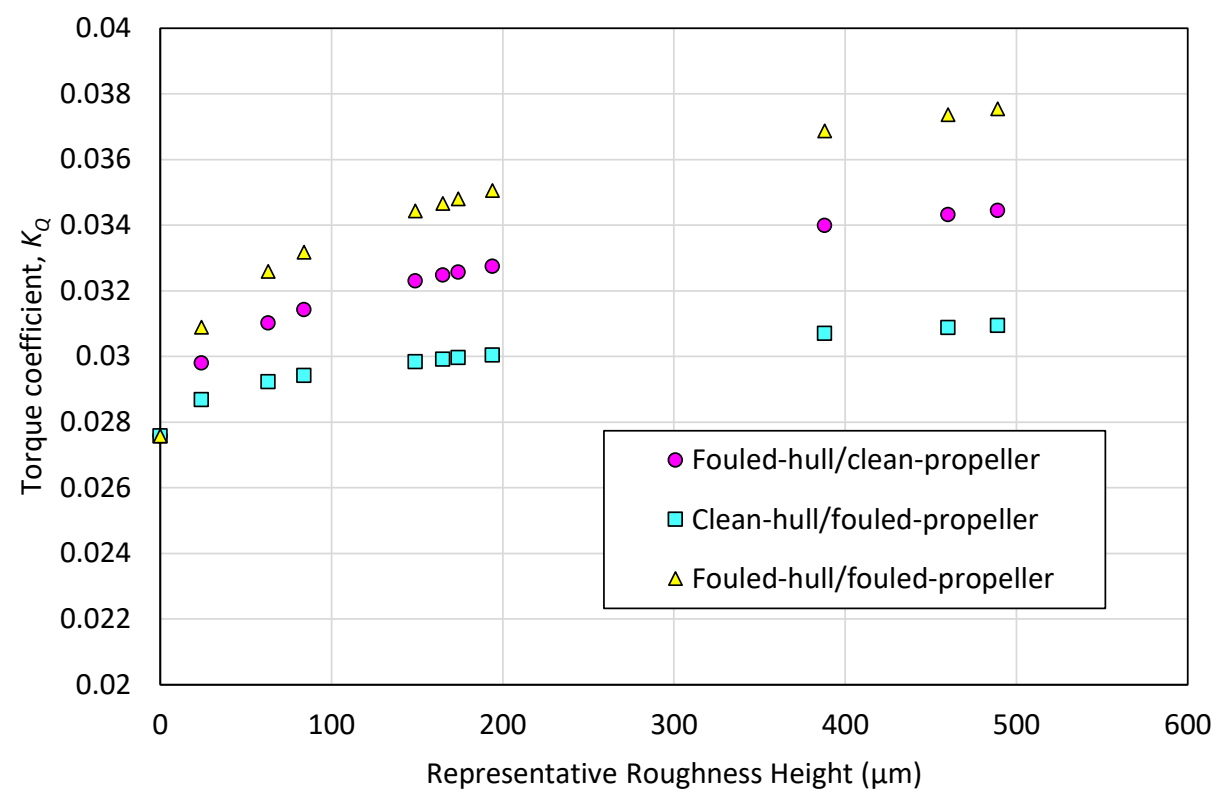

Figure 21 Torque coefficient, $K_{Q}$, at self-propulsion point under the given fouling conditions, plotted against the representative roughness heights of the surface conditions in Table 1

\subsection{Effect on advance coefficient}

Figure 22 shows the advance coefficients, $J$, at the self-propulsion points under the given fouling conditions. The $J$ values were obtained by the thrust identity method using the open water curve for the fouled propellers [37]. The decrease in the advance coefficient values $\left(J=V_{A} / n D\right)$ can mostly be attributed to the increases in the $n$ values which is shown in Figure 18. Another reason for the decrease in $J$ values can be the enlarged wake field for the fouled-hull cases and hence decelerated flow velocity upstream of the propeller, $V_{A}$, as shown by Song et al. [36].

The decreases in J values for fouled-hull/clean-propeller, clean-hull/fouled-propeller, and fouled-hull/fouledpropeller conditions at the most severe surface fouling condition (B20\%) were observed to be $-13.4 \%,-2 \%$, and $-13.3 \%$, respectively. 


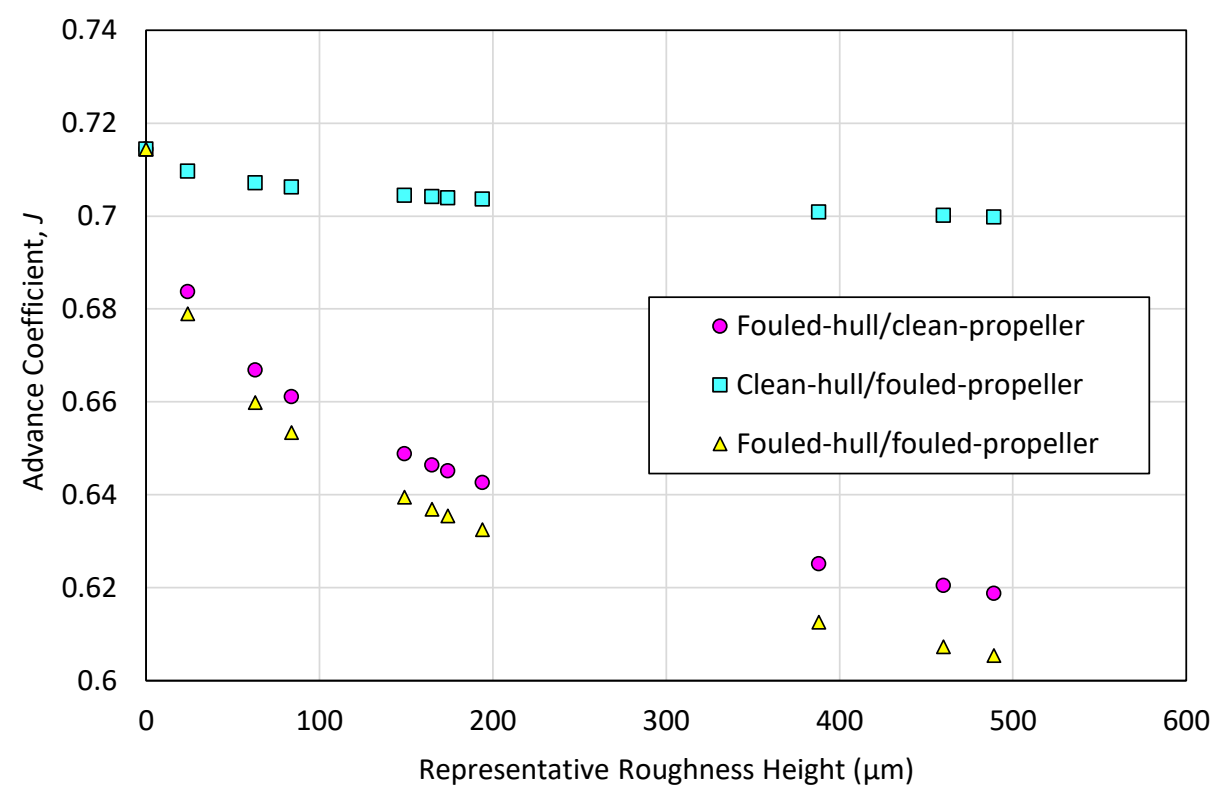

Figure 22 Advance coefficient, $J$, at self-propulsion point under the given fouling conditions, plotted against the representative roughness heights of the surface conditions in Table 1

\subsection{Effect on thrust deduction factor}

Figure 23 shows the thrust deduction factor, $1-t$, at the self-propulsion points under the given fouling conditions. Interestingly, $1-t$ values were revealed to increase (i.e. decreased thrust deduction factor, $t$ ) due to the hull fouling, which can result in improved hull efficiencies, $\eta_{H}$. While fouled-hull cases show increased $1-t$ values, clean-hull/fouled-propeller case showed slightly decreased $1-t$ values. For a similar reason, fouled-hull/cleanpropeller case showed slightly larger $1-t$ values than fouled-hullffouled-propeller case.

It is of note that although the thrust deduction factors, $t$, showed decreases due to hull-fouling, it does not necessarily mean the effect of thrust deduction is reduced. It only means, the 'ratio' between the required thrust, $T$, in self-propulsion condition and the towed ship total resistance, $R_{T}$, is reduced. That is to say, while the thrust deduction factor reduced, the absolute value of the drag owing to the thrust deduction can increase with increasing level of surface fouling, as shown in Figure 17.

The increases and decrease in $1-t$ values under fouled-hull/clean-propeller, clean-hullffouled-propeller, and fouled-hullfouled-propeller conditions at the most severe surface fouling condition (B20\%) were observed to be $5.4 \%,-0.1 \%$, and $5.2 \%$, respectively. 


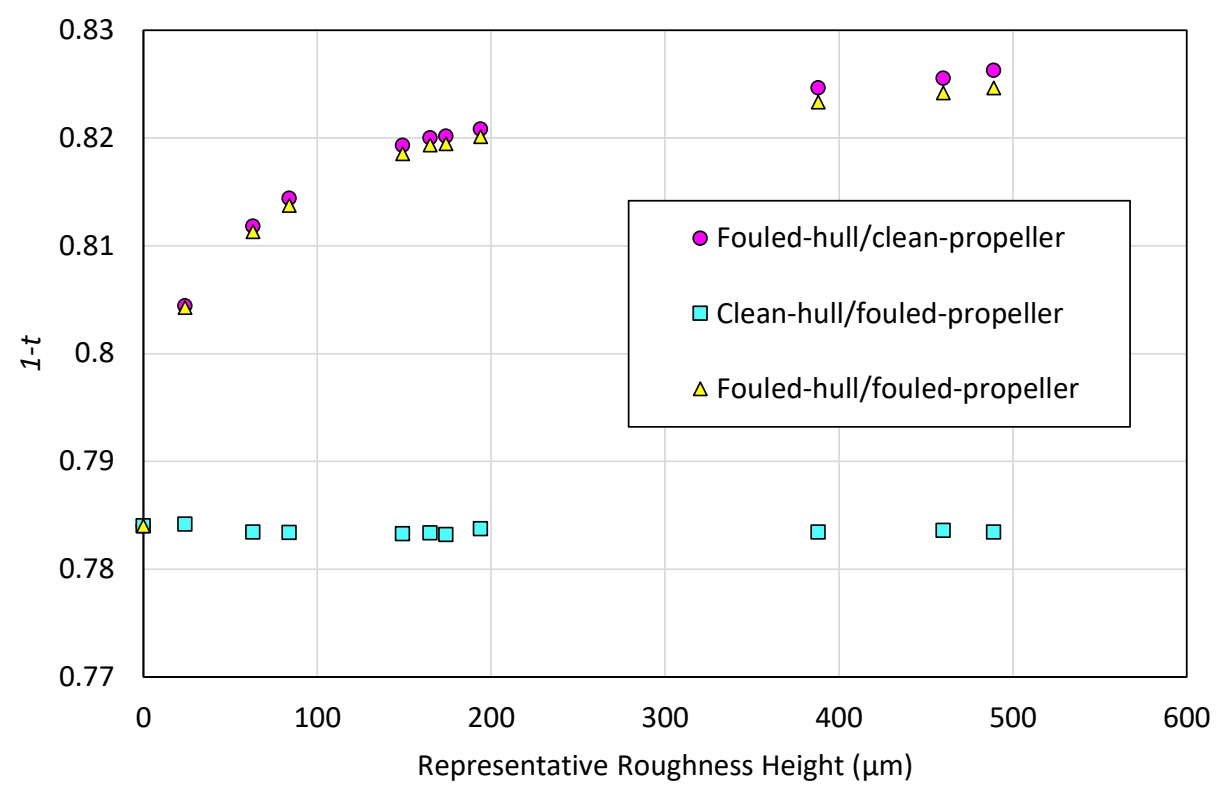

Figure 23 Thrust deduction factor, $1-t$, at self-propulsion point under the given fouling conditions, plotted against the representative roughness heights of the surface fouling conditions in Table 1

\subsection{Effect on wake fraction}

Figure 24 shows the wake fractions, $1-w_{T}$, at the self-propulsion points under the given fouling conditions. As can be seen in the figure, the $1-w_{T}$ values of the fouled-hull cases showed decreases (i.e. increased wake fraction, $w_{T}$ ), which is desirable for hull efficiency, $\eta_{H}$. This increase in wake fraction, $w_{T}$, is consistent with the increased stern wake field and nominal wake fraction, $w_{n}$, which was found by Song et al. [36].

As expected, the effect of propeller fouling on the $1-w_{T}$ values was minor. But, fouled-hull/fouled-propeller case showed slightly larger decreases than those of fouled-hull/clean-propeller case as can be seen in the figure.

The decreases in $1-w_{T}$ values under fouled-hull/clean-propeller, clean-hull/fouled-propeller, and fouledhull/fouled-propeller conditions at the most severe surface fouling condition (B20\%) were revealed to be $-6.4 \%$, $-0.1 \%$, and $-6.7 \%$, respectively. 


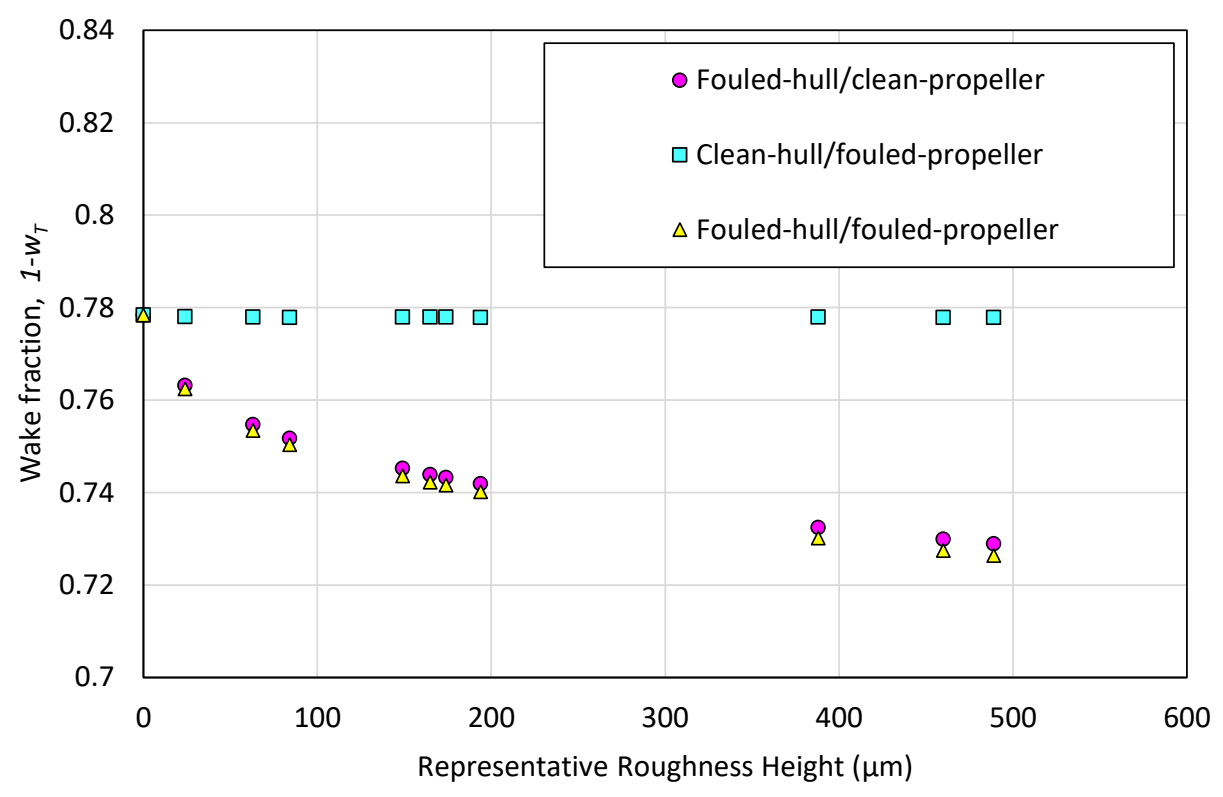

Figure 24 Wake fraction, $1-w_{T}$, at self-propulsion point under the given fouling conditions, plotted against the representative roughness heights of the surface fouling conditions in Table 1

\subsection{Effect on relative rotative efficiency and open water efficiency}

Figure 25 shows the relative rotative efficiencies, $\eta_{R}$, and propeller open water efficiencies, $\eta_{O}$, at the selfpropulsion points under the given fouling conditions. As can be seen in the figure, the $\eta_{R}$ values showed decreasing trends with both of the hull fouling and propeller fouling, but the magnitude of the decrease is smaller than that for open water efficiencies, $\eta_{O}$. The decrease in $\eta_{O}$ values can be related to the decreased advance coefficient values, $J$, which is shown in Figure 22. However, unlike the $J$ values, clean-hullffouled-propeller case showed larger decreases in $\eta_{O}$ values than fouled-hull/clean-propeller, due to that fact that the open water curves for the fouled propellers have smaller $\eta_{O}$ than those for the clean propeller.

The decreases in $\eta_{R}$ values under fouled-hull/clean-propeller, clean-hull/fouled-propeller, and fouled-hull/fouledpropeller conditions at the most severe surface fouling condition (B20\%) were observed to be $-1.9 \%,-1.2 \%$, and $-2.6 \%$, respectively. And the decreases in $\eta_{O}$ for those fouling conditions were observed to be $-8.7 \%,-15.4 \%$ and $-20.1 \%$, respectively. 


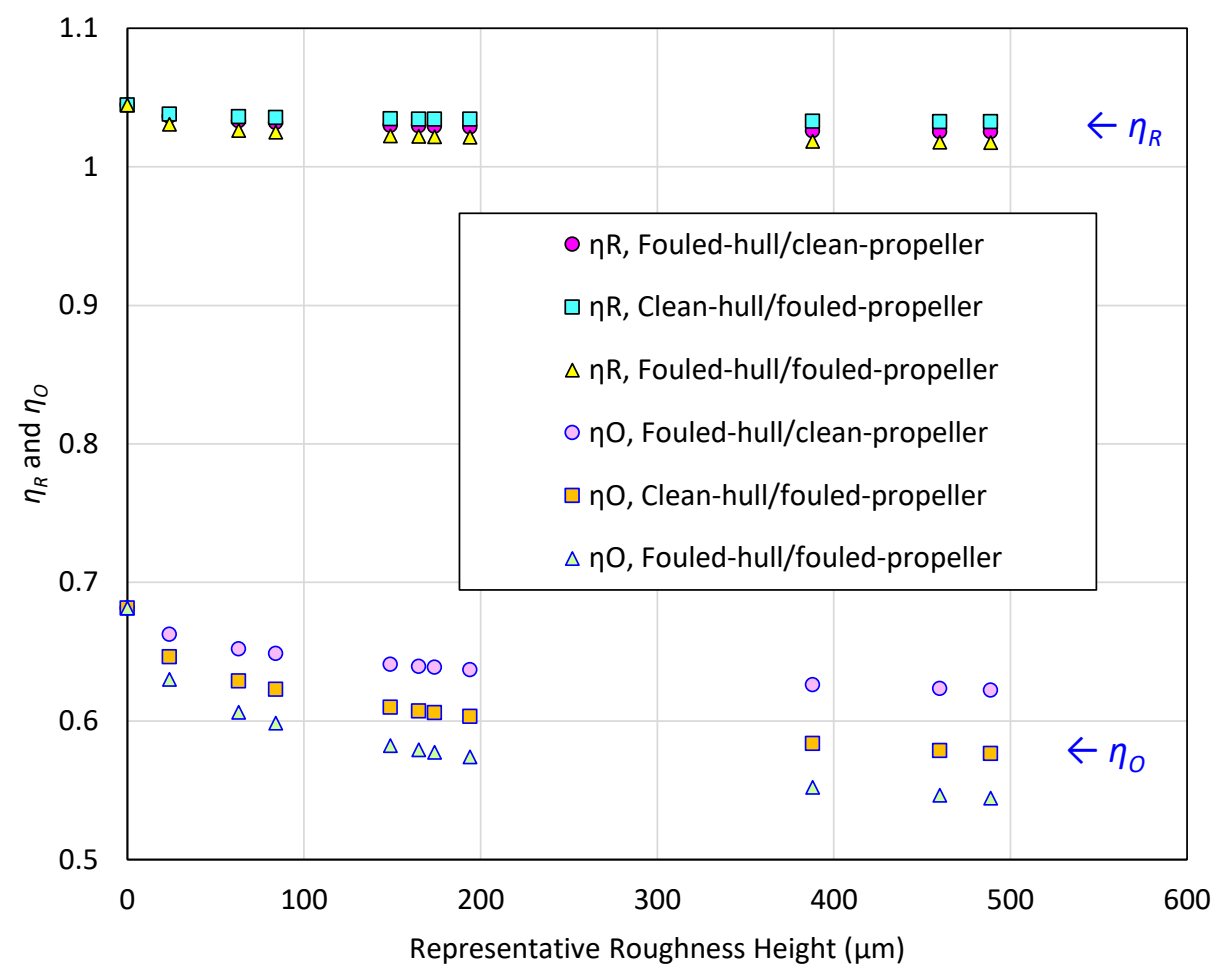

Figure 25 Relative rotative efficiency, $\eta_{R}$, and propeller open water efficiency, $\eta_{O}$, at self-propulsion point under the given fouling conditions, plotted against the representative roughness heights of the surface fouling conditions in Table 1

\subsection{Effect on hull efficiency and behind-hull efficiency}

Figure 26 compares the hull efficiencies, $\eta_{H}$, and behind-hull propeller efficiencies, $\eta_{B}$, at the self-propulsion points under the given fouling conditions. As the effect of propeller fouling on $1-t$ and $1-w_{T}$ were found to be minor, the $\eta_{H}$ values $\left(\eta_{H}=1-t / 1-w_{T}\right)$ for clean-hullffouled-propeller remained rather constant. For this reason, the $\eta_{H}$ values for the fouled-hull cases collapsed on each other. As expected in previous sections, the fouled-hull cases showed increasing trends of the $\eta_{H}$ values with increasing level of surface fouling.

When it comes to the behind-hull efficiencies, $\eta_{B}$, they showed decreases due to both of the hull and propeller fouling. As the impact of them was larger for the $\eta_{O}$ than $\eta_{R}$, the decreases in $\eta_{B}$ values $\left(\eta_{B}=\eta_{R} \eta_{O}\right)$ for the fouling conditions were found to follow the same order of the decrease in $\eta_{O}$.

The increases in $\eta_{H}$ values under fouled-hull/clean-propeller, clean-hull/fouled-propeller, and fouled-hullffouledpropeller conditions at the most severe surface fouling condition (B20\%) were observed to be $12.5 \%, 0 \%$, and $12.7 \%$, respectively. And the decreases in $\eta_{B}$ for those fouling conditions were observed to be $-10.4 \%,-16.4 \%$ and $-22.2 \%$, respectively. 


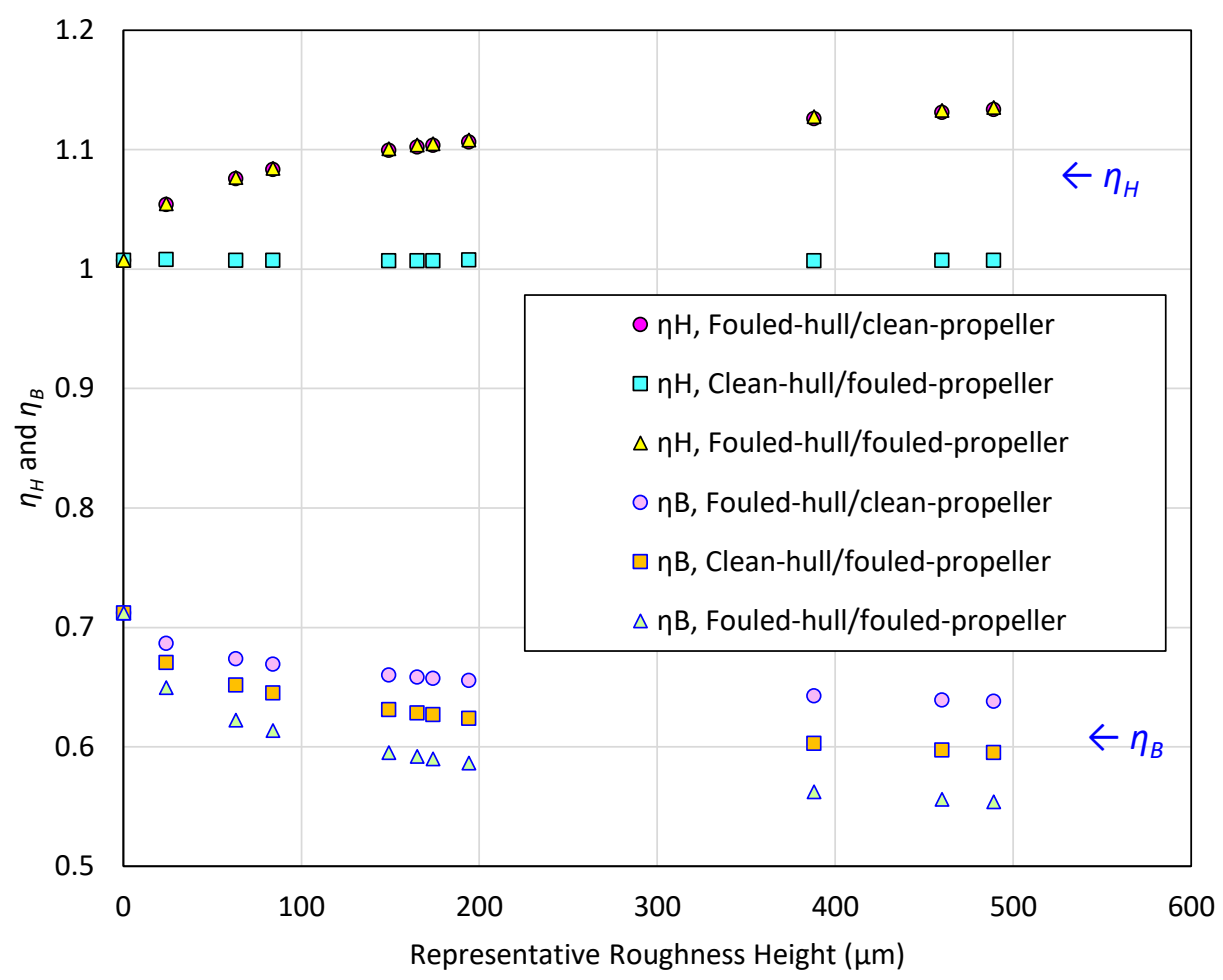

Figure 26 Hull efficiency, $\eta_{H}$, and behind-hull propeller efficiency, $\eta_{H}$, at self-propulsion point under the given fouling conditions, plotted against the representative roughness heights of the surface fouling conditions in Table 1

\subsection{Effect on propulsive efficiency}

Figure 27 shows the propulsive efficiencies, $\eta_{D}$, at the self-propulsion points under the given fouling conditions. As it was found in the previous sections that the hull efficiencies, $\eta_{H}$, are increased by hull fouling, while the behind-hull propeller efficiencies, $\eta_{B}$, are decreased by both of hull and propeller fouling, the propulsive efficiencies, $\eta_{D}=\eta_{H} \eta_{B}$, showed an interesting result.

In terms of fouled-hull/clean-propeller case, the magnitudes of increase in $\eta_{H}$ are larger than those of decrease in $\eta_{B}$, as can be seen in Figure 26. As a result, the $\eta_{\mathrm{D}}$ values for this case showed increases.

The largest reductions in $\eta_{D}$ values were observed for clean-hull/fouled-propeller case, as the $\eta_{H}$ values were constant but $\eta_{B}$ values were decreased due to the propeller fouling. On the other hand, fouled-hull/fouledpropeller case shows relatively smaller decreases in $\eta_{D}$ values owing to the increased $\eta_{H}$ values.

The increases and decrease in $\eta_{D}$ values under fouled-hull/clean-propeller, clean-hull/fouled-propeller, and fouled-hull/fouled-propeller conditions at the most severe surface fouling condition (B20\%) were observed to be $0.9 \%,-16.4 \%$, and $-12.3 \%$, respectively. 


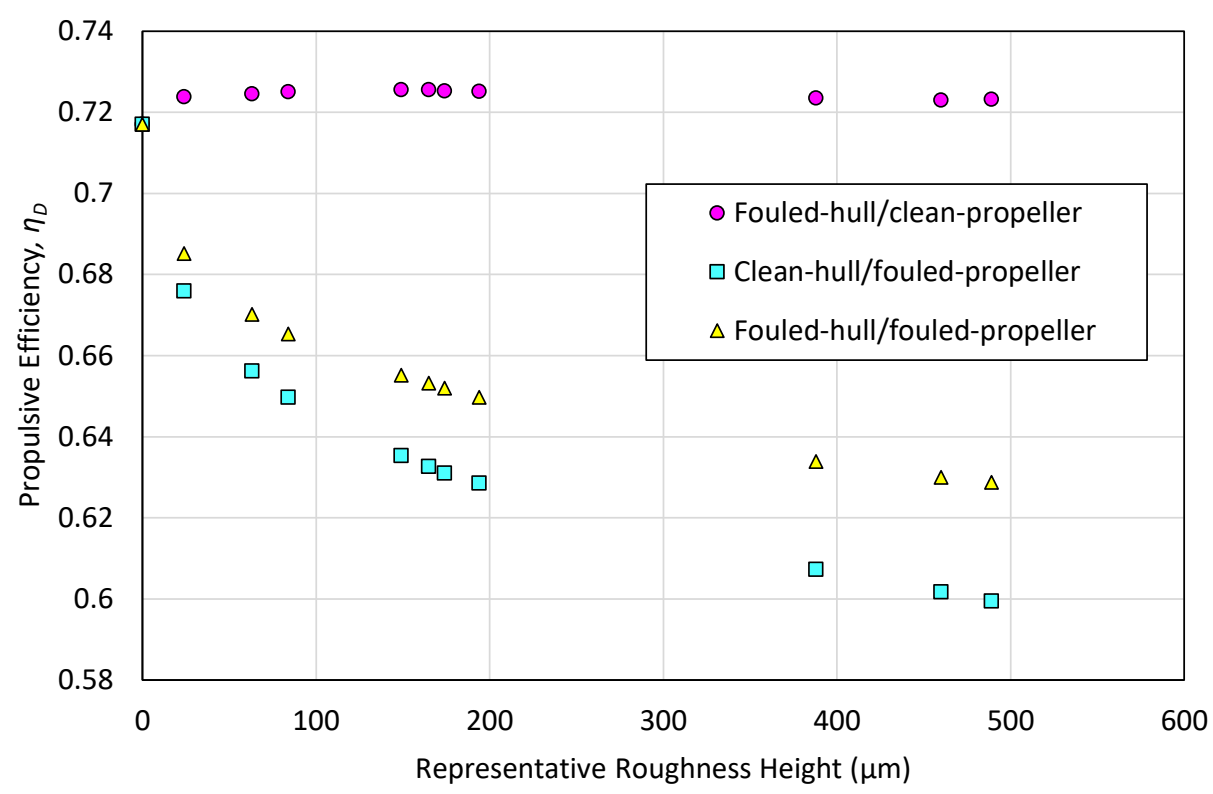

Figure 27 Propulsive efficiency, $\eta_{D}$, at self-propulsion point under the given fouling conditions, plotted against the representative roughness heights of the surface fouling conditions in Table 1

\subsection{Power penalty}

Using the simulation results, the increases in required shaft power, $S P$, under the given fouling conditions were calculated. The required shaft power can be calculated as

$$
S P=2 \pi \rho K_{Q} n^{3} D^{5}
$$

The required shaft power, $S P$, were calculated with the $K_{Q}$ and $n$ values obtained from the self-propulsion simulations under the given fouling conditions.

For comparison purposes, the required shaft powers, $S P$, for the given fouling conditions were calculated from two different methods: self-propulsion method, using the $K_{Q}$ and $n$ values directly obtained from the current selfpropulsion simulations with Equation 18, and towing/open-water method using the corresponding $K_{Q}$ and $n$ values obtained from the towed ship and propeller open water simulations [36, 37].

In towing/open-water method the required shaft power, $S P$, was determined as follows: i) The required thrust, $T$, for the given conditions are calculated as $T=R_{T} /(1-t)$, where $R_{T}$ is the total resistance under the corresponding hull fouling obtained by Song et al. [36] and $1-t$ is the thrust deduction factor of Hino [53]; ii) then the advance coefficients, $J$, of the propeller open water curves of Song et al. [37] are converted into the propeller revolutions, $n=V_{s}\left(1-w_{n}\right) /(J D)$, where $1-w_{n}$ is wake fraction for the hull fouling [36] and $V_{s}$ is the ship speed; iii) the thrust coefficients, $K_{T}$, of the open water curves are converted to thrust values as, $T=\rho n^{2} D^{4}$, and then a $n$ vs $T$ curve is obtained; iv) from the $n$ vs $T$ curve, corresponding $n$ is determined, such that the required thrust is achieved; v) $K_{Q}$ value at the corresponding $n$ (and hence $J$ ) is read from the open water curves of Song et al. [37]; vi) finally, the required shaft power, $S P$, is determined using Equation 18, with the obtained $n$ and $K_{Q}$ values.

Figure 28 compares the required shaft powers, $S P$, at the self-propulsion points under the given fouling conditions, which were obtained using self-propulsion method and towing/open-water method. As can be seen in the figure, the $S P$ values obtained from two different methods show a fair agreement in the trend, but towing/open-water method relatively under-predicted the $S P$ values compared to those obtained from self-propulsion method. 
It was observed that the $S P$ values for fouled-hull/clean-propeller case show better agreement than other cases. Considering that fouled-hull/clean-propeller case showed the smallest roughness effect on the propulsive efficiency, $\eta_{D}$, this can be deduced that the differences between the two methods arise from the fact that towing/open-water method does not properly consider the roughness effect on the propulsive efficiency, $\eta_{D}$. That is to say, this method could not consider the roughness effect on the thrust deduction factor, $1-t$, and the relative rotative efficiency, $\eta_{R}$. Also, the differences between $1-w_{n}$ and $1-w_{T}$ due to the hull-propeller interaction can be another reason for the disagreements.

However, considering the high computational cost required for the self-propulsion simulations, towing/openwater method can be considered as a reasonable alternative. It is of note that the CPU time required for selfpropulsion method was 357,864 CPU-hours $(11,544$ hours $\times 31$ cases $)$ and that for towing/open-water method was 16,115 CPU-hours $(1,348$ hours $\times 11$ cases +117 hours $\times 11$ cases $)$.

The increases in required shaft power $S P$ values obtained from the simulations, under fouled-hull/clean-propeller, clean-hullffouled-propeller, and fouled-hullfouled-propeller conditions at the most severe surface fouling condition (B20\%) were observed to be $57.8 \%, 19.2 \%$, and $81.8 \%$, respectively. And the increases calculated from towing/open-water method were $68.4 \%, 19.9 \%$ and $84.0 \%$.

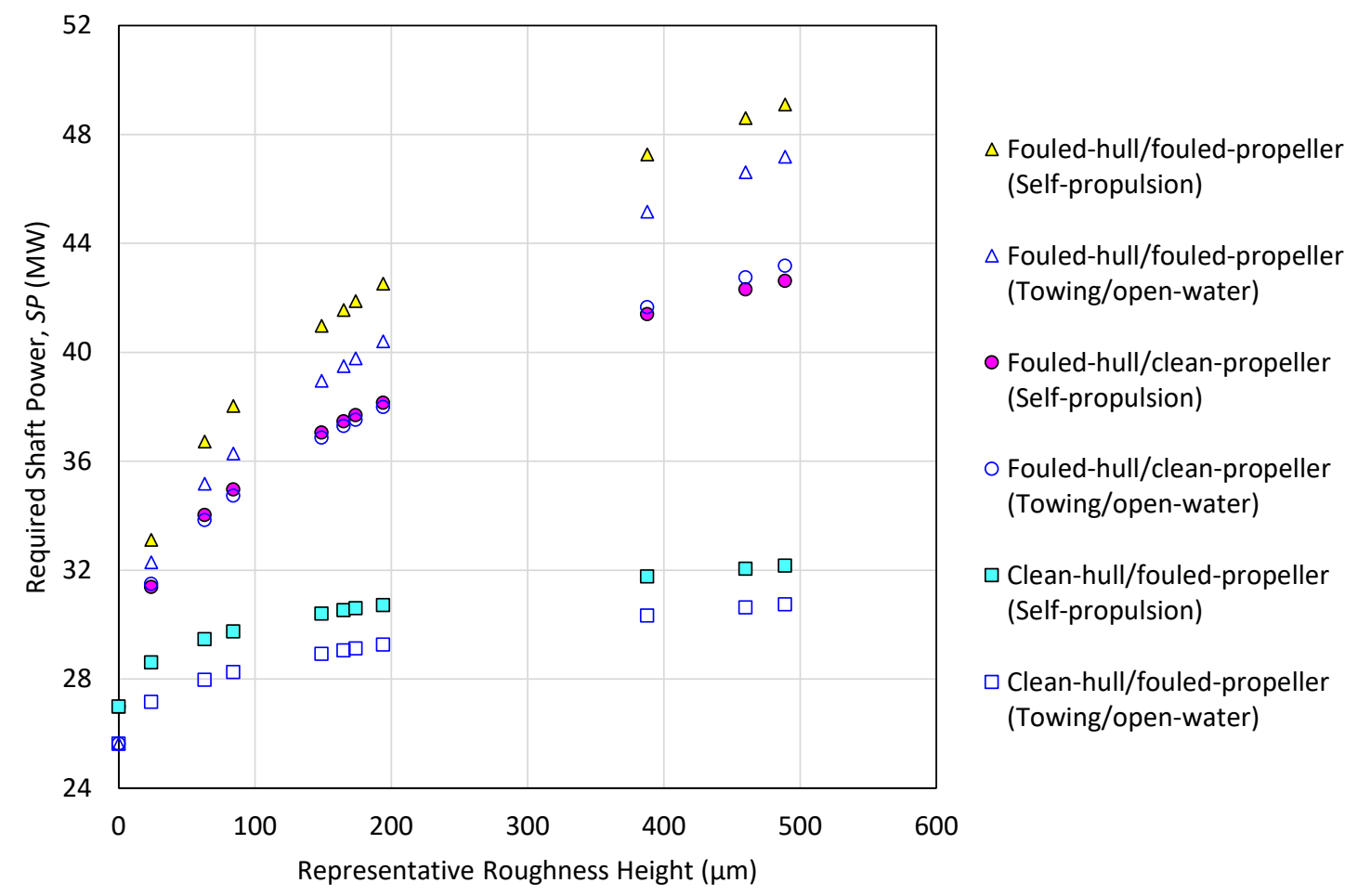

Figure 28 Required shaft power, $S P$, at self-propulsion point under the given fouling conditions, obtained from the current CFD and using the towed ship and propeller open water simulations [36, 37], plotted against the representative roughness heights of the surface fouling conditions in Table 1

\section{The effect of biofouling on flow characteristics}

\subsection{Effect on velocity distribution}

Figure 29 compares the velocity contours of $V_{x z} / V_{\text {ship }}$ on the $y=0.006 L_{p p}$ plane, under the given fouling conditions, while Figure 30 illustrates the velocity contours of $V_{x} / V_{\text {ship }}$ on the $x=0.0089 L_{p p}$ plane. It can be seen from the figures that the velocity fields are strongly affected by the hull fouling while the effect of propeller fouling is relatively negligible. The higher velocities downstream to the propeller for the fouled-hull cases can be attributed to the higher rotational speeds, $n$, as shown in Figure 18. 
Figure 29 shows the decelerated flow upstream to the propeller, and Figure 30 shows enlarged wake field for the fouled-hull cases, while the propeller fouling has almost no effect. This can be related to the effects on the wake fractions in Figure 24. Another notable point is that the fouled-hull cases have thicker boundary layers compared to the clean-hull cases, which is in correspondence with the increased $C_{T}$ values in 14, as well as the findings of Demirel et al. [31] and Song et al. [36].

The increased boundary layer thickness and enlarged wake filed can be more clearly seen in Figure 31 . In the figure, the boundary layer thickness of around the KCS hulls were represented by the contours of the turbulent kinetic energy $(T K E>0.2 \mathrm{~J} / \mathrm{kg})$. As similarly seen in the previous figures, Figure 31 illustrates increased boundary layer thicknesses and wake fields for fouled-hull cases, whereas no significant differences were found due to the propeller fouling.

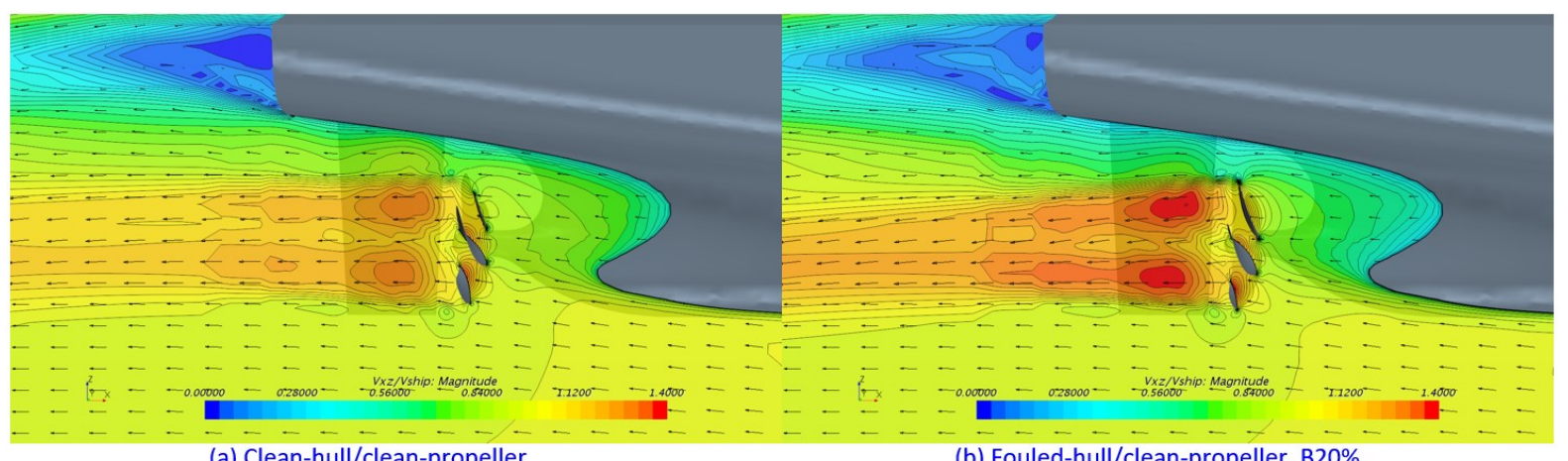

(a) Clean-hull/clean-propeller

(b) Fouled-hull/clean-propeller, B20\%

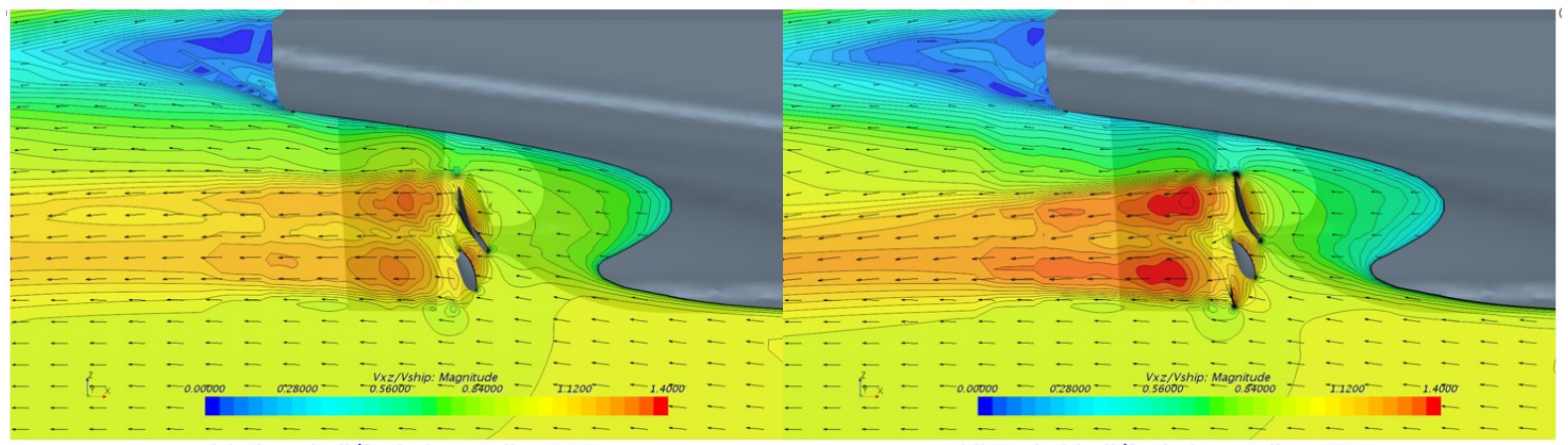

(c) Clean-hull/fouled-propeller, B20\%

(d) Fouled-hull/fouled-propeller, B20\%

Figure 29 Velocity contour of $V_{x z} / V_{\text {ship }}$ at $y=0.006 L_{p p}$, (a) clean-hull/clean-propeller, (b) fouled-hull/clean-propeller, B20\%, (c) clean-hull/fouled-propeller, B20\%, (d) fouled-hull/fouled-propeller, B20\% 


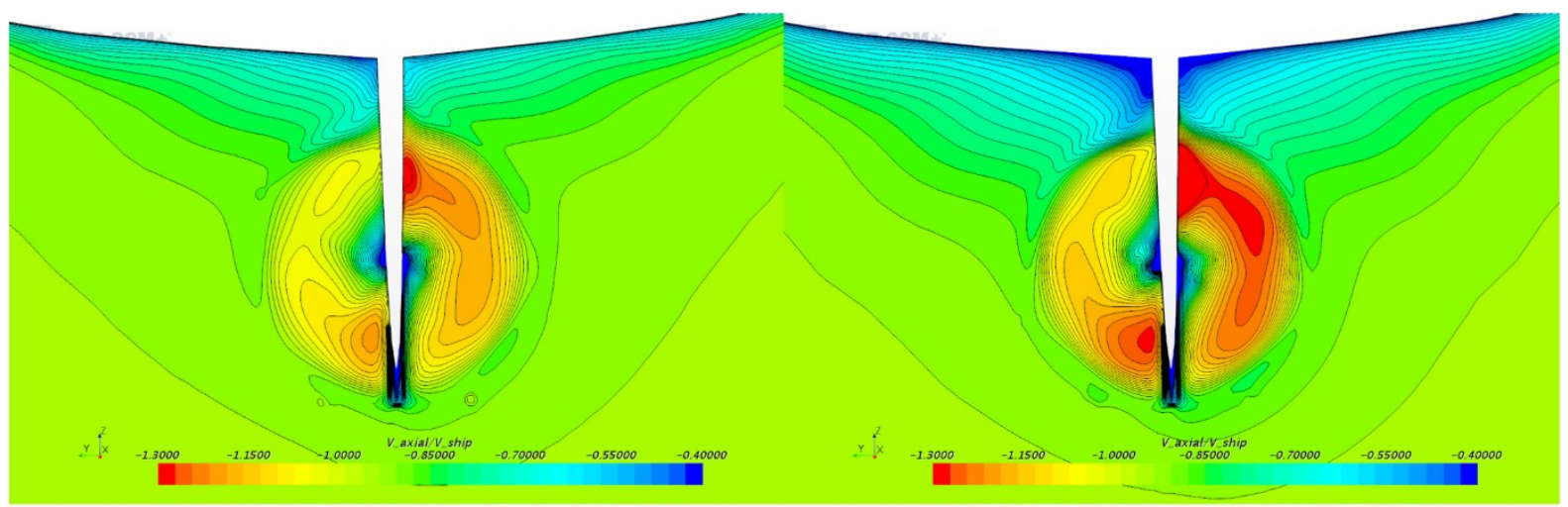

(a) Clean-hull/clean-propeller

(b) Fouled-hull/clean-propeller, B20\%

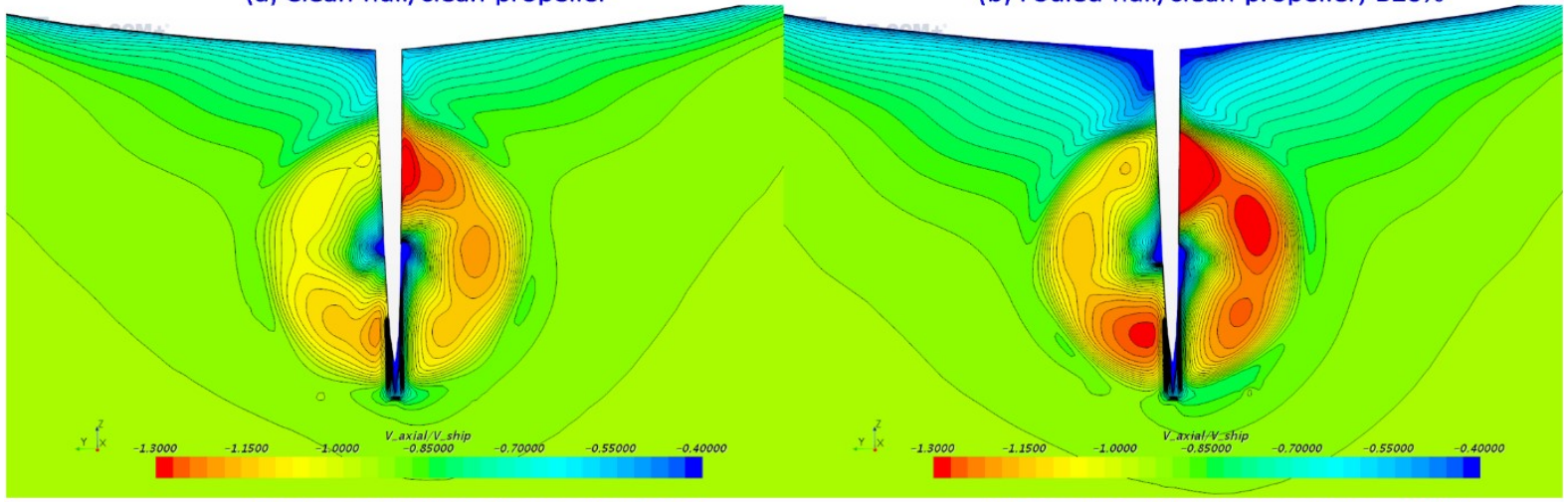

(c) Clean-hull/fouled-propeller, B20\%

(d) Fouled-hull/fouled-propeller, B20\%

Figure 30 Axial velocity contour of $V_{x} / V_{\text {ship }}$ at $x=0.0089 L_{p p}$, (a) clean-hull/clean-propeller, (b) fouled-hull/cleanpropeller, B20\%, (c) clean-hull/fouled-propeller, B20\%, (d) fouled-hull/fouled-propeller, B20\%

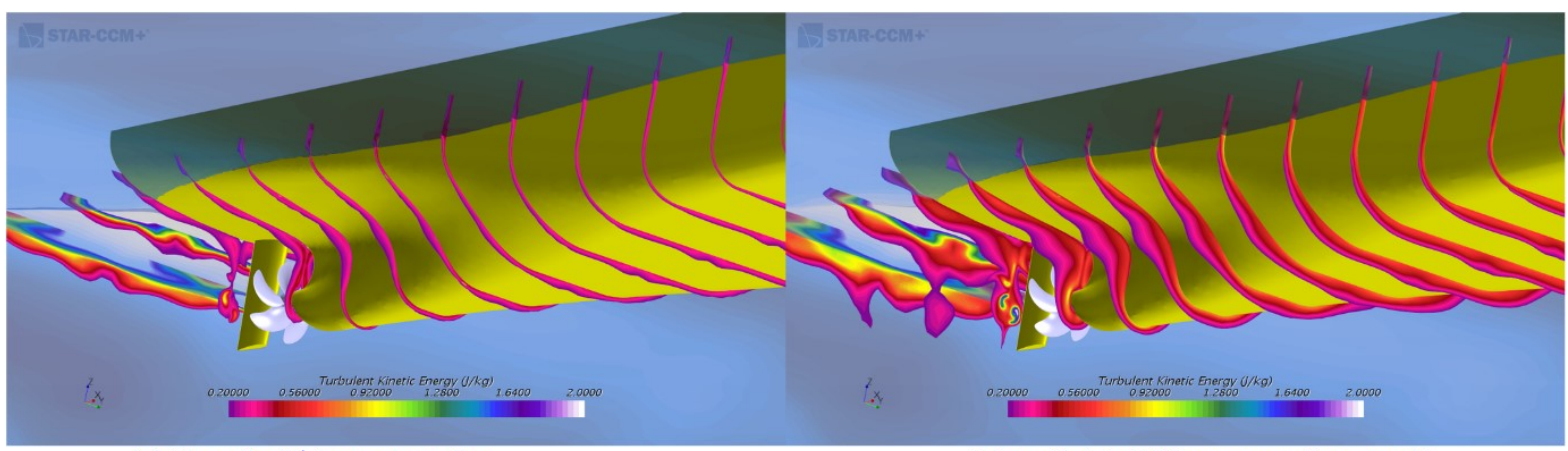

(a) Clean-hull/clean-propeller

(b) Fouled-hull/clean-propeller, B20\%

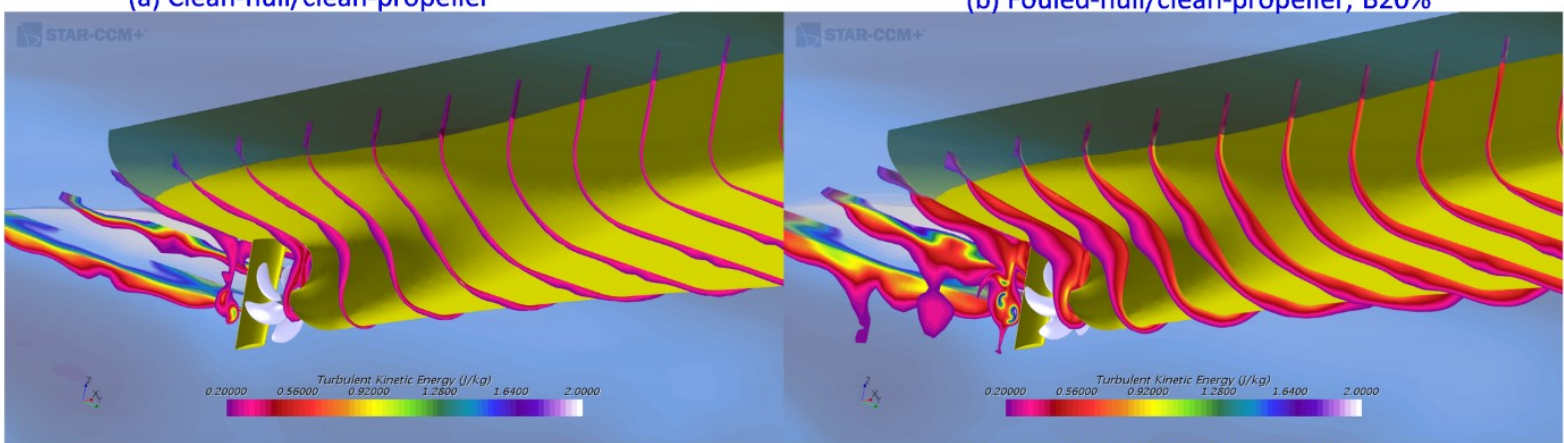

(c) Clean-hull/fouled-propeller, B20\%

(d) Fouled-hull/fouled-propeller, B20\%

Figure 31 Boundary layer represented by slices limited to the turbulent kinetic energy, (a) clean-hull/clean-propeller, (b) fouled-hull/clean-propeller, B20\%, (c) clean-hull/fouled-propeller, B20\%, (d) fouled-hull/fouled-propeller, B20\% 


\subsection{Effect on surface pressure}

Figure 32 compares the surface pressure at the stern of the ships under the different fouling conditions (a-d) and those computed under towing conditions in smooth and fouled (B20\%) conditions (e-f). The pressure was nondimensionalised by dividing it by the dynamic pressure, $1 / 2 \rho V^{2}$. From the figure, it can be observed that the fouled-hull cases have lower surface pressure than clean-hull cases, which can result in larger viscous pressure resistance, as found by Song et al. [36]. Also, compared to the towed ship cases, the cases with propeller showed smaller surface pressures, which causes thrust deduction and the increased residuary resistance, $C_{R}$, as shown in Figure 17.

It can also be observed from the figure that the effect of propeller fouling on the surface pressure of the hull and rudder is almost negligible. This finding can be related to the negligible effects of the propeller fouling on the residuary resistance coefficient, $C_{R}$, and the thrust deduction factor, $1-t$, as shown in Figure 15 and Figure 23.

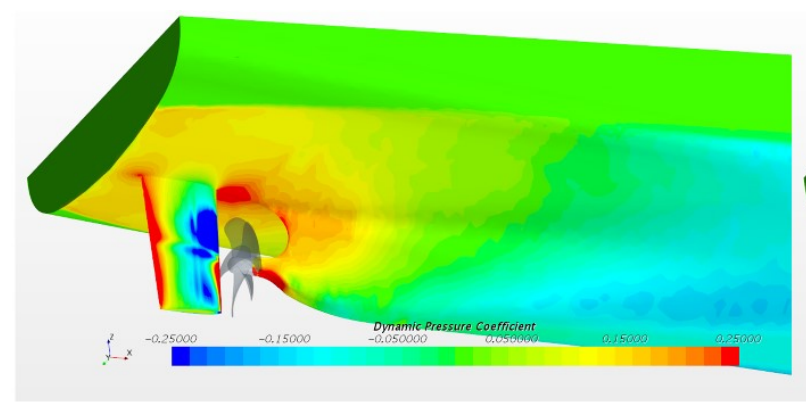

(a) Clean-hull/clean-propeller

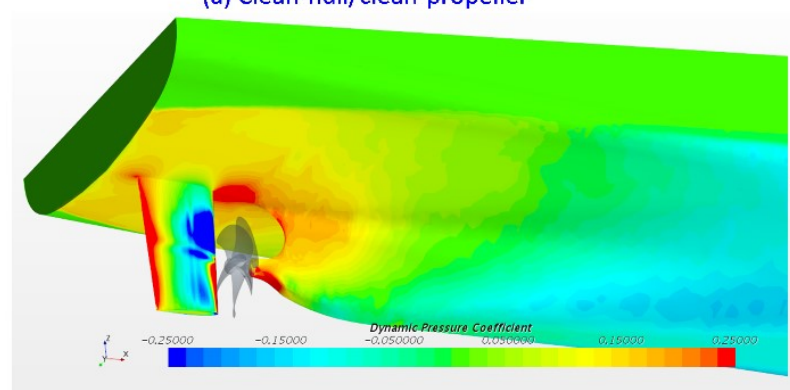

(c) Clean-hull/fouled-propeller, B20\%

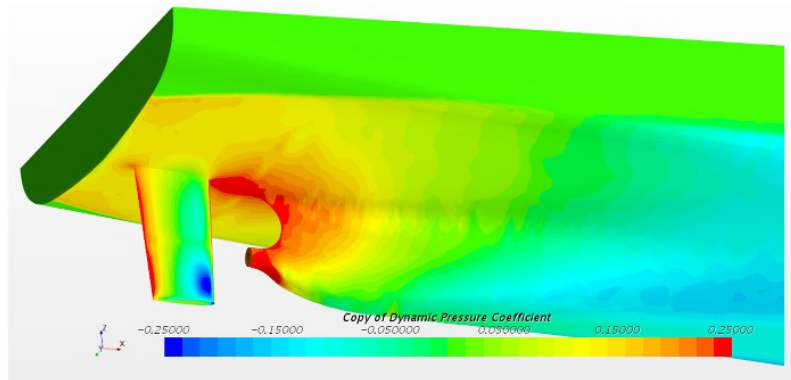

(e) Towed ship (without propeller), clean-hull

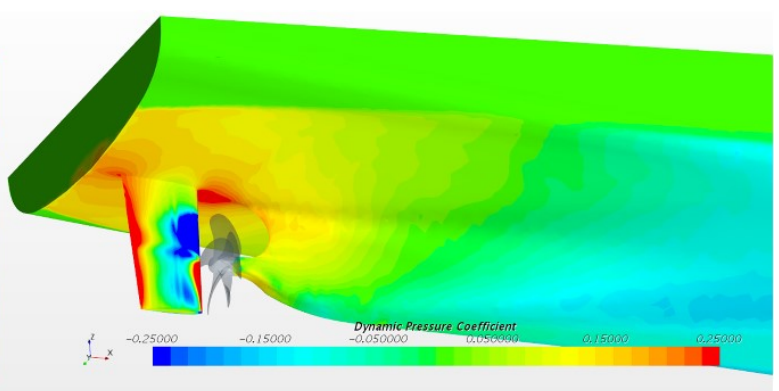

(b) Fouled-hull/clean-propeller, B20\%

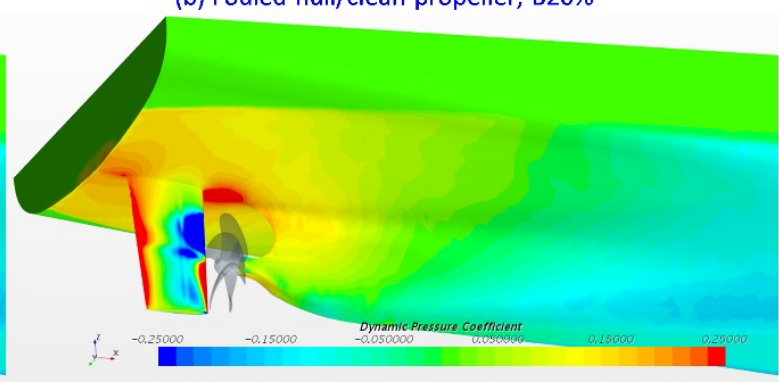

(d) Fouled-hull/fouled-propeller, B20\%

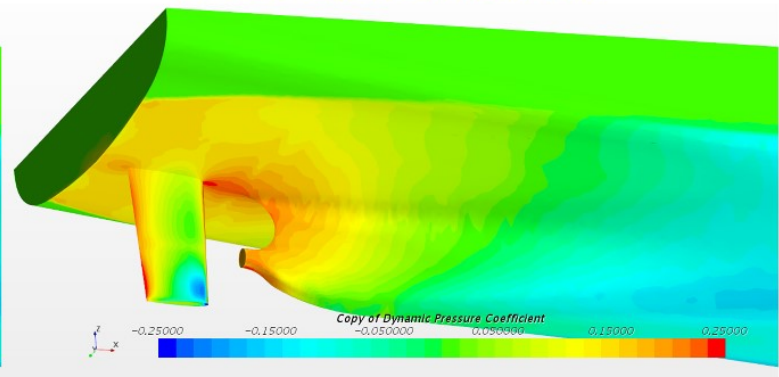

(f) Towed ship (without propeller), Fouled-hull, B20\%

Figure 32 Surface pressure distribution at the stern (a) clean-hull/clean-propeller, (b) fouled-hull/clean-propeller, B20\%, (c) clean-hull/fouled-propeller, B20\%, (d) fouled-hull/fouled-propeller, B20\%, (e) towed ship, clean-hull, (f) towed ship, fouledhull, B20\% 


\subsection{Effect on wave pattern}

Figure 33 compares the wave patterns around the hull surface of the ships in different fouling conditions. It is seen from the comparison in the figure that the wave elevations around the hull are reduced by the hull fouling, but the effect of propeller fouling is almost negligible. It is of note that his finding is consistent with the findings of Demirel et al. [31] and Song et al. [36].

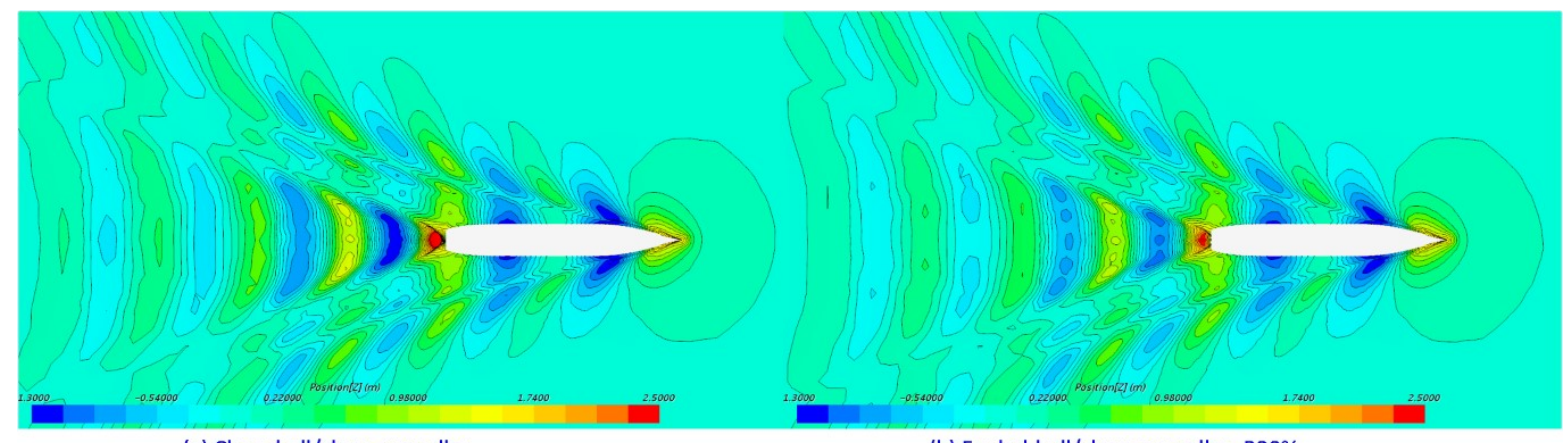

(a) Clean-hull/clean-propeller

(b) Fouled-hull/clean-propeller, B20\%

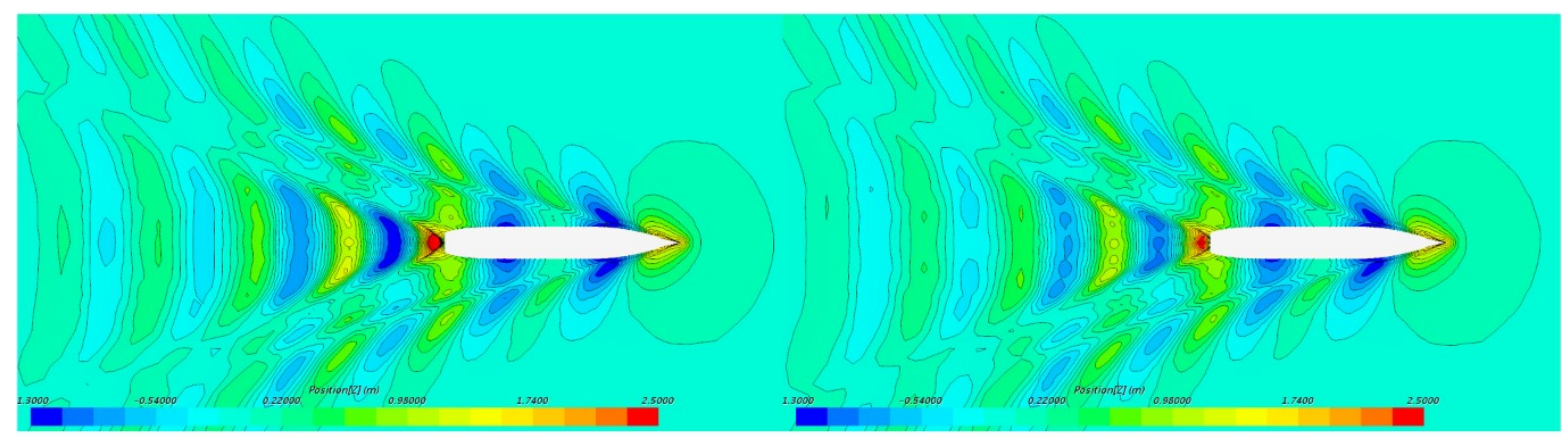

(c) Clean-hull/fouled-propeller, B20\%

(d) Fouled-hull/fouled-propeller, B20\%

Figure 33 Wave pattern around the ship, (a) clean-hull/clean-propeller, (b) fouled-hull/clean-propeller, B20\%, (c) cleanhullffouled-propeller, B20\%, (d) fouled-hullfouled-propeller, B20\%

\section{$5.4 \quad$ Effect on vorticity field}

An interesting feature was observed on the vorticity field downstream of the propeller. Figure 34 illustrates the vorticity magnitudes around the propeller at the self-propulsion points under the given surface conditions. As can be seen in the figure, the vorticity downstream to the propeller increased due to both of the hull fouling and propeller fouling. This can be seen as a consequence of the increased propeller revolutions, $n$, of those cases. Interestingly, however, when it comes to the vorticity on the leading edge of the rudders, the vorticity magnitudes for the fouled-propeller cases were observed to be reduced compared to the clean-propeller cases, although they have even higher propeller rotational speeds, $n$. This finding can be related to the finding of Song et al. [37] which showed reduced propeller hub vortex under the fouled propeller cases. This can be seen as a positive feature with regard to the problems involving rudder-propeller interaction, such as cavitation and noise. 


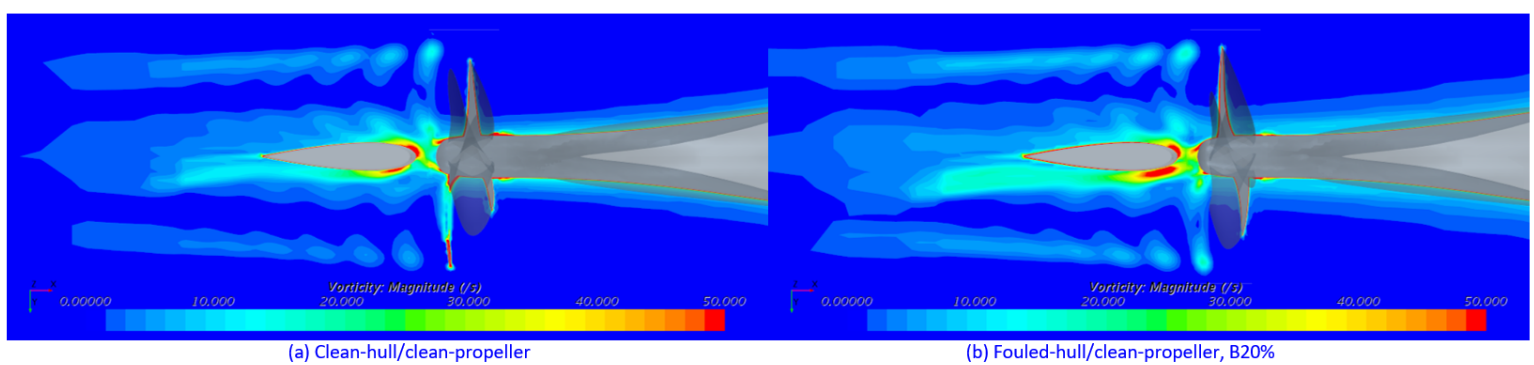

(a) Clean-hull/clean-propeller

(b) Fouled-hull/clean-propeller, B20\%

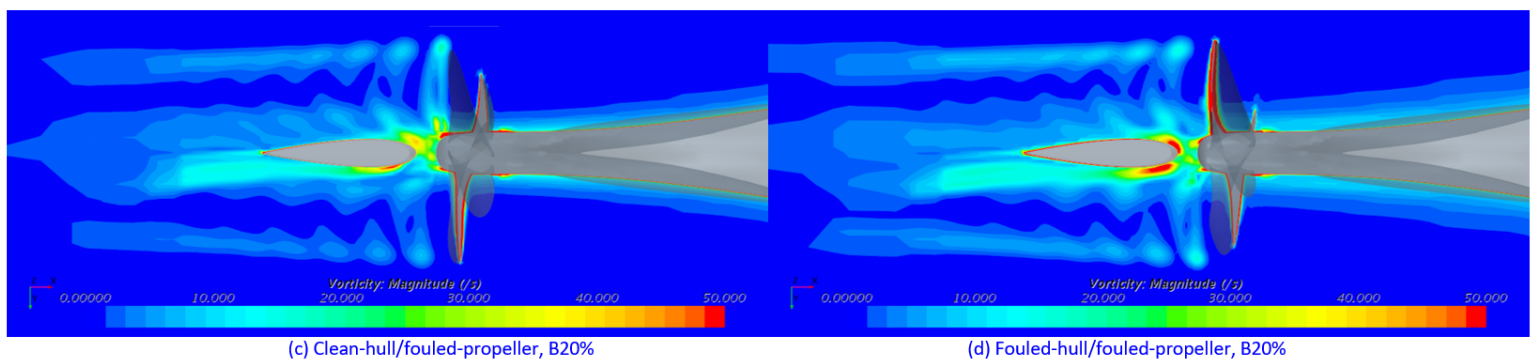

Figure 34 Vorticity contour around the propeller (bottom-up view), (a) clean-hull/clean-propeller, (b) fouled-hull/cleanpropeller, B20\%, (c) clean-hull/fouled-propeller, B20\%, (d) fouled-hull/fouled-propeller, B20\%

\section{Concluding remarks}

A CFD model for the prediction of the effect of biofouling on ship self-propulsion characteristics has been proposed. To represent the surface roughness of barnacles with varying sizes and coverages, the roughness functions obtained by Demirel et al. [26] were embedded into the wall-function of the CFD software such that the roughness effect due to the barnacles on the hull and propeller can be represented in the simulations.

A verification study was carried out to assess the numerical uncertainties of the proposed CFD model and to determine sufficient grid-spacings and time steps. Spatial and temporal convergence studies were performed using the Grid Convergence Index (GCI) method.

For the validation of the current CFD model, four different simulations were conducted namely; 'modelscale/with-rudder', 'model-scale/without-rudder', 'full-scale/with-rudder', and 'full-scale/without-rudder'. Model-scale/without-rudder simulation was compared with the experimental result and showed good agreement. The simulation results of the four different cases were compared to examine the scale effect and interactions with rudders.

Fully nonlinear URANS simulations of the full-scale KCS self-propulsion simulations were conducted in different configurations of fouling severities (barnacle sizes and coverage) and fouling scenarios (hull fouling, propeller fouling and both).

The result suggests that hull fouling increases total resistance coefficients, $C_{T}$, up to $52 \%$ with the most severe surface condition (B20\%), whereas the effect of propeller fouling on the $C_{T}$ values is negligible. The propeller rotational speed at the self-propulsion point, $n$, were observed to be increased due to both of hull fouling and propeller fouling. Interestingly, improved hull efficiencies, $\eta_{H}$ were observed for the fouled-hull cases due to the increased stern wake, $w_{T}$, and reduced thrust deduction factor, $t$, while the effect of propeller fouling was minor. On the other hand, the behind-hull efficiencies, $\eta_{B}$, showed decreases due to the hull and propeller fouling. The overall propulsive efficiencies, $\eta_{D}$, for fouled-hull/clean-propeller case showed increases whereas the other cases showed decreases. The impact on $\eta_{D}$ values for clean-hull/fouled-propeller case was found to be most critical, which showed up to $22.2 \%$ decreases with the most severe surface condition.

Power penalties due to the given fouling conditions were also calculated using the self-propulsion simulation results as well as using the towed ship and propeller open water simulations of Song et al. [36, 37]. The two different methods showed a fair agreement. The increases in the shaft power, $S P$, for fouled-hull/fouled-propeller case under the most severe surface condition, predicted from the self-propulsion method and towing/open-water method, were $81.8 \%$ and $84.0 \%$ increases, respectively. 
The roughness effect on the flow characteristics was also examined. The velocity fields at the stern showed a strong dependency of the hull fouling whereas the effects of propeller fouling were relatively minor. As expected, fouled-hull cases showed thicker boundary layers on the hull. Decelerated flow upstream to the propeller and enlarged wake field due to the hull fouling was also observed, which is consistent with the increased wake fractions.

The surface pressures under different fouling conditions were also compared together with those of towed ship simulations without the propeller. Again, the effect of propeller fouling on the surface pressure on the hull and rudder was observed to be negligible while the effect of hull fouling was clearly seen.

An interesting finding is that the reduced vorticity on the leading edge of the rudders for fouled-propeller cases, even with the higher propeller revolutions due to the propeller fouling. This finding can be seen as positive, in terms of cavitation and noise, and could be related to the finding of Song et al. [37] which showed reduced propeller hub vortex under the fouled propeller cases.

This study has provided several important findings including the effect of biofouling on the ship self-propulsion parameters and propulsive efficiencies, as well as flow characteristics around the hull. These findings can be usefully utilised for predicting the required power, fuel consumption and green-house gas emissions of ships with fouled hulls and/or propellers. However, as the feature of hull-rudder-propeller interaction is different for every different ship, the effect of biofouling can also be different for different ship types. Therefore, future pieces of work may be extending the study to cover broad types of ships including submarines.

\section{Acknowledgements}

It should be noted that the results were obtained using the ARCHIE-WeSt High Performance Computer (www.archie-west.ac.uk) based at the University of Strathclyde.

\section{References}

[1] Townsin, R. L. (2003). The Ship Hull Fouling Penalty. Biofouling, 19(sup1), 9-15. doi:10.1080/0892701031000088535

[2] Tezdogan, T., \& Demirel, Y. K. (2014). An overview of marine corrosion protection with a focus on cathodic protection and coatings. Brodogradnja, 65, 49-59.

[3] McEntee, W. (1915). Variation of frictional resistance of ships with condition of wetted surface. Trans. Soc. Nav. Arch. Mar. Eng., 24, 37-42.

[4] Hiraga, Y. (1934). Experimental investigations on the resistance of long planks and ships. Zosen Kiokai, $55,159-199$.

[5] Kempf, G. (1937). On the effect of roughness on the resistance of ships. Trans INA, 79, 109-119.

[6] Benson, J., Ebert, J., \& Beery, T. (1938). Investigation in the NACA tank fo the effect of immersion in salt water on the resistance of plates coated with different shipbottom paints. Retrieved from

[7] Watanabe, S., Nagmatsu, N., Yokoo, K., \& Kawakami, Y. (1969). The augmentation in frictional resistance due to slime. J. Kansai Soc. Nav. Arc., 131(45-51).

[8] Loeb, G., Laster, D., \& Gracik, T. (1984). The influence of microbial fouling films on hydrodynamic drag of rotating discs. In: J. D. Costlow, R. C. Tipper (Eds.), Marine Biodeterioration: An Interdisciplinary Study, 88-94.

[9] Lewkowicz, A., \& Das, D. (1986). Turbulent boundary layers on rough surface with and without a pliable overlayer: a simulation of marine fouling. International Shipbuilding Progress, 33, 174-186.

[10] Lewthwaite, J., Molland, A. \& Thomas, K. (1985). An investigation into the variation of ship skin frictional resistance with fouling. Transactions of Royal Institution of Naval Architects, 127, 269-284.

[11] Haslbeck, E. G. B. (1992). Microbial biofilm effects on drag-lab and field. Paper presented at the Ship Production Symposium Proceedings. 
[12] Schultz, M. P. (1998). The Effect of Biofilms on Turbulent Boundary Layer Structure. (PhD), Florida Institute of Technology, Melbourne, Florida, US.

[13] Schultz, M. P., \& Swain, G. W. (1999). The Effect of Biofilms on Turbulent Boundary Layers. Journal of Fluids Engineering, 121(1), 44-51. doi:10.1115/1.2822009

[14] Schultz, M. P. (2004). Frictional Resistance of Antifouling Coating Systems. Journal of Fluids Engineering, 126(6), 1039-1047. doi:10.1115/1.1845552

[15] Andrewartha, J., Perkins, K., Sargison, J., Osborn, J., Walker, G., Henderson, A., \& Hallegraeff, G. (2010). Drag force and surface roughness measurements on freshwater biofouled surfaces. Biofouling, 26, 487496.

[16] Li, C., Atlar, M., Haroutunian, M., Anderson, C., \& Turkmen, S. (2018). An experimental investigation into the effect of $\mathrm{Cu} 2 \mathrm{O}$ particle size on antifouling roughness and hydrodynamic characteristics by using a turbulent flow channel. Ocean Engineering, 159, 481-495. doi:https://doi.org/10.1016/j.oceaneng.2018.01.042

[17] Schultz, M. P. (2007). Effects of coating roughness and biofouling on ship resistance and powering. Biofouling, 23(5), 331-341. doi:10.1080/08927010701461974

[18] Demirel, Y.K., Song, S., Turan, O., Incecik, A. (2019). Practical added resistance diagrams to predict fouling impact on ship performance. Ocean Engineering. (In-press)

[19] McEntee, W. (1916). Notes from Model Basin. Transactions of the Society of Naval Architects and Marine Engineers.

[20] Taylor, D. W. (1943). The speed and power of ships: a manual of marine propulsion. Washington: U.S. G.P.O.

[21] Bengough, G. D., \& Shepheard, V. G. (1943). The corrosion and fouling of ships. Paper presented at the The Marin Corrosion Sub-committee of the Iron and Steel Institute and the British Iron and Steel Federation.

[22] Mutton, R. J., Atlar, M., \& Anderson, C. D. (2005). Drag Prevention Coatings for Marine Propellers. Paper presented at the 2nd International Symposium on Seawater Drag Reduction, Busan, Korea.

[23] Korkut, E., \& Atlar, M. (2012). An experimental investigation of the effect of foul release coating application on performance, noise and cavitation characteristics of marine propellers. Ocean Engineering, 41, 112. doi:https://doi.org/10.1016/j.oceaneng.2011.12.012

[24] Pérez, M. C., Stupak, M. E., Blustein, G., Garcia, M., \& Mårtensson Lindblad, L. (2009). 21 - Organic alternatives to copper in the control of marine biofouling. In C. Hellio \& D. Yebra (Eds.), Advances in Marine Antifouling Coatings and Technologies (pp. 554-571): Woodhead Publishing.

[25] Monty, J. P., Dogan, E., Hanson, R., Scardino, A. J., Ganapathisubramani, B., \& Hutchins, N. (2016). An assessment of the ship drag penalty arising from light calcareous tubeworm fouling. Biofouling, 32(4), 451 464. doi:10.1080/08927014.2016.1148140

[26] Demirel, Y. K., Uzun, D., Zhang, Y., Fang, H.-C., Day, A. H., \& Turan, O. (2017). Effect of barnacle fouling on ship resistance and powering. Biofouling, 33(10), 819-834. doi:10.1080/08927014.2017.1373279

[27] Gowing, S., Chang, P., Dehn, C., \& Storms, S. (2018). Measurements of biofouling drag using a 2-D channel flow apparatus with models of bio-fouled panels. Paper presented at the The 19th International Congress on Marine Corrosion and Fouling, Melbourne, Florida.

[28] Womack, K. M., Schultz, M. P., \& Meneveau, C. (2018). Effect of barnacle density on hydrodynamic drag. Paper presented at the The 19th International Congress on Marine Corrosion and Fouling, Melbourne, Florida.

[29] Granville, P. S. (1958). The frictional resistance and turbulent boundary layer of rough surfaces. J. Ship Res., 2(3), 52-74. 
[30] Granville, P. S. (1978). Similarity-law characterization methods for arbitrary hydrodynamic roughnesses. Retrieved from Bethesda, MD:

[31] Demirel, Y. K., Turan, O., \& Incecik, A. (2017). Predicting the effect of biofouling on ship resistance using CFD. Applied Ocean Research, 62, 100-118. doi:https://doi.org/10.1016/j.apor.2016.12.003

[32] Atlar, M., Yeginbayeva, I. A., Turkmen, S., Demirel, Y. K., Carchen, A., Marino, A., \& Williams, D. (2018). A Rational Approach to Predicting the Effect of Fouling Control Systems on "In-Service" Ship Performance. GMO SHIPMAR, 24(213), 5-36.

[33] Demirel, Y. K., Khorasanchi, M., Turan, O., Incecik, A., \& Schultz, M. P. (2014). A CFD model for the frictional resistance prediction of antifouling coatings. Ocean Engineering, 89, 21-31. doi:https://doi.org/10.1016/j.oceaneng.2014.07.017

[34] Farkas, A., Degiuli, N., \& Martić, I. (2018). Towards the prediction of the effect of biofilm on the ship resistance using CFD. Ocean Engineering, 167, 169-186. doi:https://doi.org/10.1016/j.oceaneng.2018.08.055

[35] Owen, D., Demirel, Y. K., Oguz, E., Tezdogan, T., \& Incecik, A. (2018). Investigating the effect of biofouling on propeller characteristics using CFD. Ocean Engineering. doi:https://doi.org/10.1016/j.oceaneng.2018.01.087

[36] Song, S., Demirel, Y. K., \& Atlar, M. (2019). An investigation into the effect of biofouling on the ship hydrodynamic characteristics using CFD. Ocean Engineering, 175, 122-137. doi:https://doi.org/10.1016/j.oceaneng.2019.01.056

[37] Song, S., Demirel, Y. K., \& Atlar, M. (2019). An investigation into the effect of biofouling on full-scale propeller performance using CFD. Paper presented at the 38th International Conference on Ocean, Offshore \& Arctic Engineering, Glasgow.

[38] Grigson, C. (1992). Drag losses of new ships caused by hull finish. Journal of Ship Research, 36, 182196.

[39] Ferziger, J. H., \& Peric, M. (2002). Computational Methods for Fluid Dynamics: Springer-Verlag Berlin Heidelberg.

[40] Menter, F. R. (1994). Two-Equation Eddy-Viscosity Turbulence Models for Engineering Applications. AIAA Journal, 32(8), 1598-1605.

[41] Kim, W. J., Van, S. H., \& Kim, D. H. (2001). Measurement of flows around modern commercial ship models. Experiments in Fluids, 31(5), 567-578. doi:10.1007/s003480100332

[42] Larsson, L., Stern, F., \& Visonneau, M. (2013). CFD in Ship Hydrodynamics-Results of the Gothenburg 2010 Workshop. In L. Eça, E. Oñate, J. García-Espinosa, T. Kvamsdal, \& P. Bergan (Eds.), MARINE 2011, IV International Conference on Computational Methods in Marine Engineering: Selected Papers (pp. $237-$ 259). Dordrecht: Springer Netherlands.

[43] Fujisawa, J., Ukon, Y., Kume, K., \& Takeshi, H. (2000). Local Velocity Field Measurements around the KCS Model. Retrieved from Tokyo: http://www.t2015.nmri.go.jp

[44] Farkas, A., Degiuli, N., \& Martić, I. (2017). Numerical simulation of viscous flow around a tanker model. Brodogradnja, 68(2).

[45] Cakici, F., Sukas, O. F., Kinaci, O. K., \& Alkan, A. D. (2017). Prediction of the vertical motions of the DTMB 5415 ship using different numerical approaches. Brodogradnja, 68(2).

[46] Vlašić, D., Degiuli, N., Farkas, A., \& Martić, I. (2018). The preliminary design of a screw propeller by means of computational fluid dynamics. Brodogradnja, 69(3).

[47] CD-Adapco. (2017). STAR-CCM+ user guide, version 12.06. 
[48] Richardson, L. F. (1910). The approximate arithmetical solution by finite differences of physical problems involving differential equations, with an application to the stresses in a masonry dam. Transcations of the Royal Society of London. Series A, 210, 307-357.

[49] Tezdogan, T., Demirel, Y. K., Kellett, P., Khorasanchi, M., Incecik, A., \& Turan, O. (2015). Full-scale unsteady RANS CFD simulations of ship behaviour and performance in head seas due to slow steaming. Ocean Engineering, 97, 186-206. doi:https://doi.org/10.1016/j.oceaneng.2015.01.011

[50] Terziev, M., Tezdogan, T., Oguz, E., Gourlay, T., Demirel, Y. K., \& Incecik, A. (2018). Numerical investigation of the behaviour and performance of ships advancing through restricted shallow waters. Journal of Fluids and Structures, 76, 185-215. doi:https://doi.org/10.1016/j.jfluidstructs.2017.10.003

[51] Celik, I. B., Ghia, U., Roache, P. J., Freitas, C. J., Coleman, H., \& Raad, P. E. (2008). Procedure for Estimation and Reporting of Uncertainty Due to Discretization in CFD Applications. Journal of Fluids Engineering, 130(7), 078001-078001-078004. doi:10.1115/1.2960953

[52] ITTC. (2011). ITTC-Recommended procedures and guidelines: practical guidelines for ship selfpropulsion CFD.

[53] Hino, T. (2005 ed). Proceedings of CFD Workshop Tokyo 2005. Retrieved from

[54] Carrica, P. M., Castro, A. M., \& Stern, F. (2010). Self-propulsion computations using a speed controller and a discretized propeller with dynamic overset grids. Journal of Marine Science and Technology, 15(4), 316330. doi:10.1007/s00773-010-0098-6

[55] Reichel, M. (2009). Influence of rudder location on propulsive characteristics of a single screw container ship. Paper presented at the First International Symposium on Marine Propulsors smp'09, Trondheim, Norway. 


\section{Appendix}

Table A. 1 Self-propulsion parameters under 'fouled-hull/clean-propeller' conditions

\begin{tabular}{|c|c|c|c|c|c|c|c|c|c|c|c|c|c|c|c|c|}
\hline $\begin{array}{l}\text { Test } \\
\text { Surface }\end{array}$ & $\begin{array}{l}\text { Representative } \\
\text { roughness } \\
\text { height }(\mu \mathrm{m})\end{array}$ & $C_{T}$ & $C_{F}$ & $C_{R}$ & $K_{T}$ & $K_{Q}$ & $\begin{array}{l}n \\
\text { (rps) }\end{array}$ & $1-t$ & $J$ & $1-\mathrm{Wt}$ & $\eta_{0}$ & $\eta_{H}$ & $\eta_{R}$ & $\eta_{B}$ & $\eta_{D}$ & $\begin{array}{l}S P \\
\text { (MW) }\end{array}$ \\
\hline Smooth & 0 & $2.675 \mathrm{E}-03$ & $1.441 \mathrm{E}-03$ & $1.234 \mathrm{E}-03$ & $1.720 \mathrm{E}-01$ & $2.757 \mathrm{E}-02$ & 1.7028 & 0.7840 & 0.7144 & 0.7784 & 0.6815 & 1.0072 & 1.0446 & 0.7119 & 0.7170 & 27.00 \\
\hline S $10 \%$ & 24 & $3.079 \mathrm{E}-03$ & $1.843 \mathrm{E}-03$ & $1.236 \mathrm{E}-03$ & $1.886 \mathrm{E}-01$ & $2.980 \mathrm{E}-02$ & 1.7445 & 0.8044 & 0.6837 & 0.7632 & 0.6625 & 1.0540 & 1.0365 & 0.6867 & 0.7238 & 31.39 \\
\hline S $20 \%$ & 63 & $3.318 \mathrm{E}-03$ & $2.070 \mathrm{E}-03$ & $1.248 \mathrm{E}-03$ & $1.978 \mathrm{E}-01$ & 3.101E-02 & 1.7686 & 0.8118 & 0.6669 & 0.7547 & 0.6521 & 1.0757 & 1.0330 & 0.6736 & 0.7246 & 34.03 \\
\hline M $10 \%$ & 84 & $3.401 \mathrm{E}-03$ & $2.148 \mathrm{E}-03$ & $1.253 \mathrm{E}-03$ & $2.009 \mathrm{E}-01$ & $3.142 \mathrm{E}-02$ & 1.7768 & 0.8144 & 0.6611 & 0.7517 & 0.6486 & 1.0834 & 1.0319 & 0.6692 & 0.7250 & 34.97 \\
\hline S $40 \%$ & 149 & $3.586 \mathrm{E}-03$ & $2.320 \mathrm{E}-03$ & $1.267 \mathrm{E}-03$ & $2.076 \mathrm{E}-01$ & $3.231 \mathrm{E}-02$ & 1.7950 & 0.8193 & 0.6488 & 0.7452 & 0.6409 & 1.0994 & 1.0297 & 0.6600 & 0.7256 & 37.06 \\
\hline M $20 \%$ & 165 & 3.622E-03 & $2.352 \mathrm{E}-03$ & $1.270 \mathrm{E}-03$ & $2.088 \mathrm{E}-01$ & $3.247 \mathrm{E}-02$ & 1.7984 & 0.8200 & 0.6464 & 0.7439 & 0.6395 & 1.1023 & 1.0294 & 0.6582 & 0.7256 & 37.47 \\
\hline В $10 \%$ & 174 & 3.642E-03 & $2.370 \mathrm{E}-03$ & $1.272 \mathrm{E}-03$ & $2.095 \mathrm{E}-01$ & $3.256 \mathrm{E}-02$ & 1.8004 & 0.8202 & 0.6452 & 0.7433 & 0.6387 & 1.1034 & 1.0292 & 0.6573 & 0.7253 & 37.70 \\
\hline S $50 \%$ & 194 & 3.682E-03 & $2.406 \mathrm{E}-03$ & $1.276 \mathrm{E}-03$ & $2.109 \mathrm{E}-01$ & $3.275 \mathrm{E}-02$ & 1.8042 & 0.8208 & 0.6426 & 0.7419 & 0.6371 & 1.1064 & 1.0287 & 0.6554 & 0.7251 & 38.15 \\
\hline M $40 \%$ & 388 & $3.963 \mathrm{E}-03$ & $2.658 \mathrm{E}-03$ & $1.305 \mathrm{E}-03$ & $2.204 \mathrm{E}-01$ & 3.399E-02 & 1.8311 & 0.8247 & 0.6251 & 0.7324 & 0.6263 & 1.1259 & 1.0260 & 0.6426 & 0.7235 & 41.40 \\
\hline M 50\% & 460 & 4.040E-03 & $2.726 \mathrm{E}-03$ & $1.314 \mathrm{E}-03$ & $2.229 \mathrm{E}-01$ & 3.433E-02 & 1.8384 & 0.8255 & 0.6205 & 0.7299 & 0.6234 & 1.1310 & 1.0254 & 0.6392 & 0.7230 & 42.31 \\
\hline B $20 \%$ & 489 & $4.067 \mathrm{E}-03$ & $2.751 \mathrm{E}-03$ & $1.316 \mathrm{E}-03$ & $2.238 \mathrm{E}-01$ & $3.444 \mathrm{E}-02$ & 1.8409 & 0.8263 & 0.6188 & 0.7290 & 0.6224 & 1.1335 & 1.0252 & 0.6380 & 0.7232 & 42.62 \\
\hline
\end{tabular}

Table A. 2 Self-propulsion parameters under 'clean-hullffouled-propeller' conditions

\begin{tabular}{|c|c|c|c|c|c|c|c|c|c|c|c|c|c|c|c|c|}
\hline $\begin{array}{l}\text { Test } \\
\text { Surface }\end{array}$ & $\begin{array}{l}\text { Representative } \\
\text { roughness } \\
\text { height }(\mu \mathrm{m})\end{array}$ & $C_{T}$ & $C_{F}$ & $C_{R}$ & $K_{T}$ & $K_{Q}$ & $\begin{array}{l}n \\
\text { (rps) }\end{array}$ & $1-t$ & $J$ & $1-\mathrm{Wt}$ & $\eta_{0}$ & $\eta_{H}$ & $\eta_{R}$ & $\eta_{B}$ & $\eta_{D}$ & $\begin{array}{l}S P \\
(\mathrm{MW})\end{array}$ \\
\hline Smooth & 0 & $2.675 \mathrm{E}-03$ & $1.441 \mathrm{E}-03$ & $1.234 \mathrm{E}-03$ & $1.720 \mathrm{E}-01$ & $2.757 \mathrm{E}-02$ & 1.7028 & 0.7840 & 0.7144 & 0.7784 & 0.6815 & 1.0072 & 1.0446 & 0.7119 & 0.7170 & 27.00 \\
\hline S $10 \%$ & 24 & $2.676 \mathrm{E}-03$ & $1.441 \mathrm{E}-03$ & $1.234 \mathrm{E}-03$ & $1.699 \mathrm{E}-01$ & $2.869 \mathrm{E}-02$ & 1.7133 & 0.7842 & 0.7097 & 0.7781 & 0.6462 & 1.0078 & 1.0379 & 0.6707 & 0.6759 & 28.62 \\
\hline S $20 \%$ & 63 & $2.678 \mathrm{E}-03$ & $1.442 \mathrm{E}-03$ & $1.236 \mathrm{E}-03$ & $1.689 \mathrm{E}-01$ & $2.923 \mathrm{E}-02$ & 1.7192 & 0.7834 & 0.7071 & 0.7779 & 0.6289 & 1.0071 & 1.0361 & 0.6516 & 0.6562 & 29.46 \\
\hline M $10 \%$ & 84 & $2.678 \mathrm{E}-03$ & $1.442 \mathrm{E}-03$ & $1.236 \mathrm{E}-03$ & $1.685 \mathrm{E}-01$ & $2.942 \mathrm{E}-02$ & 1.7211 & 0.7834 & 0.7063 & 0.7778 & 0.6229 & 1.0072 & 1.0356 & 0.6451 & 0.6497 & 29.75 \\
\hline S $40 \%$ & 149 & $2.679 \mathrm{E}-03$ & $1.442 \mathrm{E}-03$ & $1.237 \mathrm{E}-03$ & $1.676 \mathrm{E}-01$ & $2.983 \mathrm{E}-02$ & 1.7256 & 0.7833 & 0.7045 & 0.7779 & 0.6098 & 1.0069 & 1.0346 & 0.6309 & 0.6353 & 30.41 \\
\hline M $20 \%$ & 165 & $2.679 \mathrm{E}-03$ & $1.442 \mathrm{E}-03$ & $1.237 \mathrm{E}-03$ & $1.675 \mathrm{E}-01$ & $2.991 \mathrm{E}-02$ & 1.7264 & 0.7834 & 0.7042 & 0.7779 & 0.6073 & 1.0070 & 1.0344 & 0.6282 & 0.6326 & 30.53 \\
\hline В $10 \%$ & 174 & $2.679 \mathrm{E}-03$ & $1.442 \mathrm{E}-03$ & $1.237 \mathrm{E}-03$ & $1.674 \mathrm{E}-01$ & $2.996 \mathrm{E}-02$ & 1.7270 & 0.7832 & 0.7039 & 0.7779 & 0.6060 & 1.0068 & 1.0343 & 0.6268 & 0.6310 & 30.61 \\
\hline S $50 \%$ & 194 & $2.677 \mathrm{E}-03$ & $1.442 \mathrm{E}-03$ & $1.235 \mathrm{E}-03$ & $1.672 \mathrm{E}-01$ & $3.004 \mathrm{E}-02$ & 1.7275 & 0.7838 & 0.7037 & 0.7779 & 0.6032 & 1.0076 & 1.0342 & 0.6238 & 0.6286 & 30.73 \\
\hline M $40 \%$ & 388 & $2.678 \mathrm{E}-03$ & $1.442 \mathrm{E}-03$ & $1.236 \mathrm{E}-03$ & $1.659 \mathrm{E}-01$ & $3.070 \mathrm{E}-02$ & 1.7346 & 0.7834 & 0.7009 & 0.7779 & 0.5838 & 1.0071 & 1.0329 & 0.6030 & 0.6072 & 31.78 \\
\hline M 50\% & 460 & $2.677 \mathrm{E}-03$ & $1.442 \mathrm{E}-03$ & $1.235 \mathrm{E}-03$ & $1.655 \mathrm{E}-01$ & $3.087 \mathrm{E}-02$ & 1.7363 & 0.7836 & 0.7001 & 0.7779 & 0.5785 & 1.0073 & 1.0326 & 0.5974 & 0.6017 & 32.06 \\
\hline В $20 \%$ & 489 & $2.678 \mathrm{E}-03$ & $1.442 \mathrm{E}-03$ & $1.236 \mathrm{E}-03$ & $1.654 \mathrm{E}-01$ & 3.094E-02 & 1.7371 & 0.7834 & 0.6998 & 0.7779 & 0.5766 & 1.0071 & 1.0325 & 0.5953 & 0.5995 & 32.18 \\
\hline
\end{tabular}


Table A. 3 Self-propulsion parameters under 'fouled-hullffouled-propeller' conditions

\begin{tabular}{llccccccccccccccccccc}
\hline $\begin{array}{l}\text { Test } \\
\text { Surface }\end{array}$ & $\begin{array}{l}\text { Representative } \\
\text { roughness } \\
\text { height }(\mu \mathrm{m})\end{array}$ & & $C_{T}$ & $C_{F}$ & $C_{R}$ & $K_{T}$ & $K_{Q}$ & $n(\mathrm{rps})$ & $1-t$ & $J$ & $1-\mathrm{Wt}$ & $\eta_{O}$ & $\eta_{H}$ & $\eta_{R}$ & $\eta_{B}$ & $\eta_{D}$ & $\begin{array}{l}S P \\
(\mathrm{MW})\end{array}$ \\
\hline Smooth & 0 & $2.675 \mathrm{E}-03$ & $1.441 \mathrm{E}-03$ & $1.234 \mathrm{E}-03$ & $1.720 \mathrm{E}-01$ & $2.757 \mathrm{E}-02$ & 1.7028 & 0.7840 & 0.7144 & 0.7784 & 0.6815 & 1.0072 & 1.0446 & 0.7119 & 0.7170 & 27.00 \\
S 10\% & 24 & $3.080 \mathrm{E}-03$ & $1.844 \mathrm{E}-03$ & $1.236 \mathrm{E}-03$ & $1.865 \mathrm{E}-01$ & $3.089 \mathrm{E}-02$ & 1.7548 & 0.8043 & 0.6790 & 0.7624 & 0.6302 & 1.0549 & 1.0308 & 0.6496 & 0.6852 & 33.11 \\
S 20\% & 63 & $3.320 \mathrm{E}-03$ & $2.070 \mathrm{E}-03$ & $1.250 \mathrm{E}-03$ & $1.944 \mathrm{E}-01$ & $3.260 \mathrm{E}-02$ & 1.7844 & 0.8113 & 0.6599 & 0.7535 & 0.6064 & 1.0768 & 1.0263 & 0.6224 & 0.6701 & 36.74 \\
M 10\% & 84 & $3.404 \mathrm{E}-03$ & $2.149 \mathrm{E}-03$ & $1.255 \mathrm{E}-03$ & $1.970 \mathrm{E}-01$ & $3.317 \mathrm{E}-02$ & 1.7947 & 0.8137 & 0.6534 & 0.7504 & 0.5986 & 1.0844 & 1.0250 & 0.6136 & 0.6654 & 38.04 \\
S 40\% & 149 & $3.590 \mathrm{E}-03$ & $2.320 \mathrm{E}-03$ & $1.270 \mathrm{E}-03$ & $2.027 \mathrm{E}-01$ & $3.443 \mathrm{E}-02$ & 1.8171 & 0.8185 & 0.6395 & 0.7436 & 0.5822 & 1.1008 & 1.0224 & 0.5952 & 0.6552 & 40.98 \\
M 20\% & 165 & $3.626 \mathrm{E}-03$ & $2.353 \mathrm{E}-03$ & $1.273 \mathrm{E}-03$ & $2.038 \mathrm{E}-01$ & $3.467 \mathrm{E}-02$ & 1.8214 & 0.8193 & 0.6369 & 0.7423 & 0.5791 & 1.1038 & 1.0220 & 0.5918 & 0.6533 & 41.56 \\
B 10\% & 174 & $3.645 \mathrm{E}-03$ & $2.371 \mathrm{E}-03$ & $1.275 \mathrm{E}-03$ & $2.043 \mathrm{E}-01$ & $3.480 \mathrm{E}-02$ & 1.8239 & 0.8195 & 0.6354 & 0.7416 & 0.5775 & 1.1050 & 1.0217 & 0.5900 & 0.6520 & 41.88 \\
S 50\% & 194 & $3.685 \mathrm{E}-03$ & $2.407 \mathrm{E}-03$ & $1.278 \mathrm{E}-03$ & $2.055 \mathrm{E}-01$ & $3.506 \mathrm{E}-02$ & 1.8286 & 0.8201 & 0.6325 & 0.7401 & 0.5742 & 1.1081 & 1.0213 & 0.5864 & 0.6497 & 42.53 \\
M 40\% & 388 & $3.969 \mathrm{E}-03$ & $2.660 \mathrm{E}-03$ & $1.310 \mathrm{E}-03$ & $2.133 \mathrm{E}-01$ & $3.688 \mathrm{E}-02$ & 1.8627 & 0.8234 & 0.6126 & 0.7302 & 0.5521 & 1.1276 & 1.0184 & 0.5622 & 0.6339 & 47.27 \\
M 50\% & 460 & $4.047 \mathrm{E}-03$ & $2.728 \mathrm{E}-03$ & $1.319 \mathrm{E}-03$ & $2.154 \mathrm{E}-01$ & $3.736 \mathrm{E}-02$ & 1.8719 & 0.8242 & 0.6073 & 0.7275 & 0.5464 & 1.1329 & 1.0177 & 0.5561 & 0.6300 & 48.61 \\
B 20\% & 489 & $4.075 \mathrm{E}-03$ & $2.753 \mathrm{E}-03$ & $1.322 \mathrm{E}-03$ & $2.161 \mathrm{E}-01$ & $3.754 \mathrm{E}-02$ & 1.8752 & 0.8247 & 0.6054 & 0.7264 & 0.5443 & 1.1352 & 1.0175 & 0.5538 & 0.6287 & 49.10 \\
\hline
\end{tabular}

